\title{
Proposed standardized definitions for vertical resolution and uncertainty in the NDACC lidar ozone and temperature algorithms - Part 2: Ozone DIAL uncertainty budget
}

\author{
Thierry Leblanc ${ }^{1}$, Robert J. Sica ${ }^{2}$, Joanna A. E. van Gijsel ${ }^{3}$, Sophie Godin-Beekmann ${ }^{4}$, Alexander Haefele ${ }^{5}$, \\ Thomas Trickl $^{6}$, Guillaume Payen ${ }^{7}$, and Gianluigi Liberti ${ }^{8}$ \\ ${ }^{1}$ Jet Propulsion Laboratory, California Institute of Technology, Wrightwood, CA 92397, USA \\ ${ }^{2}$ Department of Physics and Astronomy, The University of Western Ontario, London, Canada \\ ${ }^{3}$ Royal Netherlands Meteorological Institute (KNMI), Bilthoven, the Netherlands \\ ${ }^{4}$ LATMOS-IPSL, CNRS-INSU, Paris, France \\ ${ }^{5}$ Meteoswiss, Payerne, Switzerland \\ ${ }^{6}$ Karlsruher Institut für Technologie, IMK-IFU, Garmisch-Partenkirchen, Germany \\ ${ }^{7}$ Observatoire des Sciences de l'Univers de La Réunion, CNRS and Université de la Réunion (UMS3365), \\ Saint Denis de la Réunion, France \\ ${ }^{8}$ ISAC-CNR, Via Fosso del Cavaliere 100, 00133 Rome, Italy \\ Correspondence to: Thierry Leblanc (thierry.leblanc@jpl.nasa.gov)
}

Received: 6 April 2016 - Published in Atmos. Meas. Tech. Discuss.: 25 April 2016

Revised: 22 July 2016 - Accepted: 27 July 2016 - Published: 25 August 2016

\begin{abstract}
A standardized approach for the definition, propagation, and reporting of uncertainty in the ozone differential absorption lidar data products contributing to the Network for the Detection for Atmospheric Composition Change (NDACC) database is proposed. One essential aspect of the proposed approach is the propagation in parallel of all independent uncertainty components through the data processing chain before they are combined together to form the ozone combined standard uncertainty.

The independent uncertainty components contributing to the overall budget include random noise associated with signal detection, uncertainty due to saturation correction, background noise extraction, the absorption cross sections of $\mathrm{O}_{3}$, $\mathrm{NO}_{2}, \mathrm{SO}_{2}$, and $\mathrm{O}_{2}$, the molecular extinction cross sections, and the number densities of the air, $\mathrm{NO}_{2}$, and $\mathrm{SO}_{2}$. The expression of the individual uncertainty components and their step-by-step propagation through the ozone differential absorption lidar (DIAL) processing chain are thoroughly estimated. All sources of uncertainty except detection noise imply correlated terms in the vertical dimension, which requires knowledge of the covariance matrix when the lidar signal is vertically filtered. In addition, the covariance terms
\end{abstract}

must be taken into account if the same detection hardware is shared by the lidar receiver channels at the absorbed and non-absorbed wavelengths.

The ozone uncertainty budget is presented as much as possible in a generic form (i.e., as a function of instrument performance and wavelength) so that all NDACC ozone DIAL investigators across the network can estimate, for their own instrument and in a straightforward manner, the expected impact of each reviewed uncertainty component. In addition, two actual examples of full uncertainty budget are provided, using nighttime measurements from the tropospheric ozone DIAL located at the Jet Propulsion Laboratory (JPL) Table Mountain Facility, California, and nighttime measurements from the JPL stratospheric ozone DIAL located at Mauna Loa Observatory, Hawai'i.

\section{Introduction}

The present article is the second of three companion papers that provide a comprehensive description of recent recommendations made to the Network for Detection of Strato- 
spheric Change (NDACC) lidar community for the standardization of vertical resolution and uncertainty in the NDACC lidar data processing algorithms. NDACC (http://www.ndsc. ncep.noaa.gov/) comprises more than 20 ground-based lidar instruments dedicated to the long-term monitoring of atmospheric composition and to the validation of space-borne measurements of Earth's atmosphere from satellites. The lidar instruments within the network use a wide variety of methodologies and technologies to measure key atmospheric parameters, making it very challenging to archive measurement and analysis information consistently between research groups. Consistency is a critical aspect of long-term trend studies, intercomparisons, and validation studies.

Until now, there has been no comprehensive effort within NDACC to facilitate a standardization of the definitions and approaches used to report vertical resolution and uncertainty in the NDACC ozone lidar data products. To help fill this gap, an International Space Science Institute (ISSI) international team of experts (http://www.issibern.ch/aboutissi/ mission.html) (henceforth ISSI team) was formed with the objective of providing physically meaningful recommendations on the use of standardized definitions for vertical resolution, and on the use of standardized definitions and approaches for the treatment of uncertainty in the NDACC ozone and temperature lidar retrievals. The recommendations and proposed approaches are compiled in a report, referred to in the rest of this paper as the ISSI team report (Leblanc et al., 2016a).

Our first companion paper (Part 1) (Leblanc et al., 2016b) is exclusively dedicated to the ISSI team recommendations for standardized definitions of vertical resolution. The present article (Part 2) provides a detailed description of the approach proposed by the ISSI team for a standardized treatment of uncertainty in the ozone differential absorption lidar (DIAL) retrievals. Another companion paper (Part 3) (Leblanc et al., 2016c) presents a similar approach for the standardized treatment of uncertainty in the temperature lidar retrievals.

Uncertainties in ozone DIAL measurements have been discussed since the early development of the DIAL technique (Mégie et al., 1977). Early publications dealt with the optimization of the wavelengths pairs for tropospheric and stratospheric ozone measurements, taking into account the measurement's error budget (e.g., Mégie and Menzies, 1980; Pelon and Mégie, 1982; Papayannis et al., 1990). In the framework of the NDACC, various groups have set up lidar instruments for the measurement of ozone in the troposphere and stratosphere. They have generally described their lidar systems with a detailed assessment of the measurement errors (e.g., Godin, 1987; Uchino and Tabata, 1991; McDermid et al., 1990; Papayannis et al., 1990; McGee et al., 1991; Godin-Beekmann et al., 2003). In addition, intercomparison campaigns set up in the framework of NDACC have assessed the evaluation of lidar measurement uncertainties (see http://ndacc-lidar.org/ for more information on NDACC li- dars). In the present paper, we made specific efforts to present a standardized and consistent approach for the introduction and propagation of several traceable uncertainty components that ultimately impact the retrieved ozone profile uncertainty. The proposed approach was designed so that it can be implemented consistently by most NDACC ozone lidar investigators.

The fundamentals of uncertainty with a metrological reference are briefly reviewed in Sect. 2. Based on these fundamentals, a standardized measurement model for the retrieval of ozone using the DIAL method is proposed in Sect. 3. Based on this model, detailed step-by-step expressions for the propagation of uncertainty through the ozone lidar algorithm are then provided in Sect. 4. In this section, quantitative estimates of each uncertainty component are provided in a generic manner whenever possible. Finally, two examples of uncertainty budgets taken from actual NDACC ozone DIAL measurements (nighttime measurement conditions) are provided in Sect. 5, followed by a short summary and conclusion. The reader should refer to the ISSI team report (Leblanc et al., 2016a) for aspects that are not fully described in the present article.

\section{Proposed reference definition: combined standard uncertainty}

The definition of uncertainty recommended by the ISSI team for use by all NDACC lidar measurements is the combined standard uncertainty. It originates in the two internationally recognized reference documents endorsed by the Bureau International des Poids et Mesures (BIPM), namely the International Vocabulary of Basic and General Terms in Metrology (abbreviated "VIM") (JCGM 200, 2008a, 2012), and the Guide to the Expression of Uncertainty in Measurement (abbreviated "GUM") (JCGM 100, 2008b). These two documents and their supplements provide a complete framework for the treatment of uncertainty.

In a metrological sense (article 2.26 of the VIM) (JCGM 200,2012 ), uncertainty is a "non-negative parameter characterizing the dispersion of the quantity values being attributed to a measurand based on the information used". Measurement uncertainty includes components arising from systematic effects, as well as the definitional (or "intrinsic") uncertainty, i.e., the practical minimum uncertainty achievable in any measurement. It may be a standard deviation or the half width of an interval with a stated coverage probability. The particular case of "standard uncertainty" is defined in article 2.30 of the VIM (JCGM 200, 2012), as "the measurement uncertainty expressed as a standard deviation".

\subsection{Standard uncertainty}

Standard uncertainty is a particular case of the more general context of "expanded uncertainty", which defines "an 
Table 1. Correspondence between key values of coverage factor and level of confidence for two common probability distributions.

\begin{tabular}{l|ll}
\hline \multicolumn{2}{c}{$\begin{array}{c}\text { Level of confidence } \\
p(\%)\end{array}$} & $\begin{array}{l}\text { Coverage } \\
\text { factor } k\end{array}$ \\
\cline { 1 - 2 } $\begin{array}{l}\text { Rectangular } \\
\text { distribution }\end{array}$ & $\begin{array}{l}\text { Normal } \\
\text { distribution }\end{array}$ \\
\hline 57.74 & 68.27 & 1 \\
95 & 90 & 1.645 \\
& & 1.65 \\
& 95 & 1.96 \\
99 & 95.45 & 2 \\
& 99 & 2.576 \\
& 99.73 & 3 \\
\hline
\end{tabular}

interval about the result of a measurement that may be expected to encompass a large fraction of the distribution of values that could reasonably be attributed to the measurand" (JCGM 100, 2008). Expanded uncertainty $U$ is expressed as a multiple of the standard uncertainty $u$, the scaling factor being the "coverage factor" $k$ so that $U=k u$. The value of $k$ that produces an interval corresponding to a specified level of confidence requires detailed knowledge of the probability distribution characterized by the measurement result and its combined standard uncertainty. In measurement situations where the probability distribution characterized by a measurement and its uncertainty is approximately normal, and the effective degrees of freedom of $u$ is of significant size (typically greater than 10), taking $k=2$ produces an interval having an approximate level of confidence $p=95.5 \%$. Similarly, taking $k=3$ produces an interval having an approximate level of confidence $p=99.7 \%$. Correspondence between several key values of $k$ and $p$ for the normal and rectangular probability distributions is reported in Table 1. The ISSI team recommended definition of standard uncertainty $(k=1)$ is commonly referred to as " $1 \sigma$ uncertainty", which for a normal probability distribution, corresponds to an interval of confidence of approximately $68 \%$.

\subsection{Combined standard uncertainty}

In complex measurement techniques such as lidar, the retrieved species profile depends on multiple instrumental and physical parameters (see Sect. 3), and the notion of "measurement model" needs to be introduced. In a metrological sense, a measurement model is defined as a "mathematical relation among all quantities known to be involved in a measurement" (VIM art. 2.48; JCGM 200, 2012). The measurement model can be written as follows:

$Y=f\left(X_{1}, X_{2}, \ldots, X_{N},\right)$,

where $Y$ is the output quantity in the measurement model (the retrieved species profile), and the $X_{n}(n=1,2, \ldots, N)$ are the input quantities in this model. The function $f$ describing the measurement model can be written for individual values $y$ of the quantity $Y$ in a Taylor-expanded form:

$$
\begin{aligned}
y= & f\left(x_{1}, x_{2}, \ldots, x_{N}\right)=y_{0}+\sum_{n=1}^{N} \frac{\partial y}{\partial x_{n}} x_{n} \\
& +\frac{1}{2} \sum_{n=1}^{N} \sum_{m=1}^{N} \frac{\partial^{2} y}{\partial x_{n} \partial x_{m}} x_{n} x_{m} \\
& +\frac{1}{3 !} \sum_{n=1}^{N} \sum_{m=1}^{N} \sum_{l=1}^{N} \frac{\partial^{3} y}{\partial x_{n} \partial x_{m} \partial x_{l}} x_{n} x_{m} x_{l}+\ldots
\end{aligned}
$$

In the case of a small-disturbance approximation such as the estimation of measurement and retrieval uncertainty, the nonlinearity of the function $Y$ is generally considered small enough so that the terms of order 2 and higher in the Taylor expansion can be neglected. This will be our assumption in the rest of this work, which leads to the first-order expression of the measurement model:

$y=f\left(x_{1}, x_{2}, \ldots, x_{N}\right)=y_{0}+\sum_{n=1}^{N} \frac{\partial y}{\partial x_{n}} x_{n}$.

The true values of a model's input quantities are unknown. These quantities are characterized by probability distributions and should be treated mathematically as random variables (JCGM 100, 2008b). These distributions describe the respective probabilities of their true values lying in different intervals, and are assigned based on available knowledge. Each input quantity $x_{n}$ can therefore be assigned a standard uncertainty $u_{n}$, characterizing its distribution.

The output quantity combined standard uncertainty $u_{y}$ is defined in article art. 2.31 of the VIM (JCGM 200, 2012) as the "standard measurement uncertainty that is obtained using the individual standard measurement uncertainties associated with the input quantities in a measurement model". Uncertainty components $u_{n}$ can either be estimated by type A or type B evaluations. Both types of evaluation are based on probability distributions and the uncertainty components resulting from either type are quantified by variances or standard deviations (JCGM 100, 2008b). A type A standard uncertainty is obtained from a probability density function derived from an observed frequency distribution, while a type $B$ standard uncertainty is obtained from an assumed probability density function based on the degree of belief that an event will occur, using best available knowledge. If some of the input quantities are correlated, covariances must be taken into account. In these conditions, the combined standard uncertainty is the estimated standard deviation associated with the result, and is equal to the positive square root of the combined variance obtained from all variance and covariance components using the "law of propagation of uncertainty" 
(art. 5.2 of the GUM, JCGM 100, 2008):

$$
\begin{aligned}
u_{y}^{2} & =\sum_{n=1}^{N} \sum_{m=1}^{N} \frac{\partial y}{\partial x_{n}} \frac{\partial y}{\partial x_{m}} \operatorname{cov}\left(x_{n}, x_{m}\right) \\
& =\sum_{n=1}^{N}\left(\frac{\partial y}{\partial x_{n}}\right)^{2} u_{n}^{2}+2 \sum_{m=1}^{N-1} \sum_{n=m+1}^{N} \frac{\partial y}{\partial x_{n}} \frac{\partial y}{\partial x_{m}} \operatorname{cov}\left(x_{n}, x_{m}\right) .
\end{aligned}
$$

The covariance between two random variables $X_{1}$ and $X_{2}$ with estimates $x_{1}$ and $x_{2}$ is defined by

$\operatorname{cov}\left(x_{1}, x_{2}\right)=\overline{\left(x_{1}-\overline{x_{1}}\right)\left(x_{2}-\overline{x_{2}}\right)}$.

The horizontal bar symbolizing the mean is expressed as follows:

$\bar{x}=\frac{1}{N_{\mathrm{P}}} \sum_{i_{\mathrm{P}}=1}^{N_{\mathrm{P}}} x\left(i_{\mathrm{P}}\right)$.

Equation (4) can also be expressed in terms of correlation coefficient $r_{n m}$ instead of covariance:

$$
\begin{aligned}
u_{y}^{2}= & \sum_{n=1}^{N}\left(\frac{\partial y}{\partial x_{n}}\right)^{2} u_{n}^{2} \\
& +\sum_{m=1}^{N}\left(\sum_{n=1(n \neq m)}^{N} \frac{\partial y}{\partial x_{n}} \frac{\partial y}{\partial x_{m}} r_{n m} u_{n} u_{m}\right),
\end{aligned}
$$

with the correlation coefficients $r_{n m}$ defined as

$r_{n m}=\frac{\operatorname{cov}\left(x_{n}, x_{m}\right)}{u_{n} u_{m}}$.

Correlations between input quantities cannot be ignored if present and significant. The associated covariances should be evaluated experimentally if feasible by varying the correlated input quantities (type A evaluation of covariance), or by using the pool of available information on the correlated variability of the quantities in question (type B evaluation of covariance). In type A evaluations, the default assumption is made that the distribution best describing an input quantity is a Gaussian distribution. When the uncertainty is evaluated from a small number of indication values, the corresponding distribution can be taken as a $t$ distribution (JCGM 100, $2008 \mathrm{~b})$. For a type B evaluation, the only available information is that $X_{n}$ lies in a specified interval $[a, b]$. In such a case, knowledge of the quantity can be characterized by a rectangular probability distribution with limits $a$ and $b$. If different information is available, a probability distribution consistent with that information should be used (JCGM 104, 2009). In the case of ozone DIAL measurements, both types of evaluation are found, typically type $\mathrm{A}$ for the random uncertainty associated with detection noise and type B for all other uncertainty sources (see upcoming sections).

\subsection{Minimizing correlation between input quantities for actual measurements}

The terms "systematic uncertainties" and "systematic errors", widely used in the literature, are mathematically too ambiguous to be easily assimilated into the analytical expressions described in the GUM (JCGM 100, 2008) for the propagation of uncertainty. This terminology should be avoided and will therefore not be used here unless it explicitly refers to the terminology used in specific cited works. "Systematic component" refers to a component known to be present consistently in multiple samples of the same sampling population and owing to one or several well-identified systematic effects. For this reason a significant degree of correlation between measured samples is implied. It is only after reported systematic effects have been characterized by a randomized uncertainty component for each sample, and by a well-known correlation matrix within the sampling population, that they can contribute to the analytical implementation of the combined uncertainty budget. The term "randomize" here consists of computing the value of an uncertainty component arising from a systematic effect using a probability distribution obtained from a Type-B evaluation.

If an uncertainty component arising from a systematic effect cannot be randomized or if the covariance matrix within the sampling population cannot be computed, then this systematic effect cannot be accounted for in the uncertainty budget and it must be removed before measurements are made. If a systematic effect is reported as a nonzero (positive or negative) bias with the assumption that the value of this bias is known, then the measured samples must be corrected for this value before a combined uncertainty can be computed, and an uncertainty component characterizing the correction procedure must be introduced into the combined uncertainty budget. In order to preserve the full independence of a measurement, corrections for systematic effects must rely on the physical processes altering the measurement, and therefore must be applied to the input quantities $X_{i}$, not the output quantity $Y$.

The key aspect of the approach proposed hereafter is to carefully identify the independent input quantities impacting the ozone DIAL measurement model. Once all corresponding uncertainty components of systematic behavior have been randomized, applying the law of propagation of variance (Eq. 4) to multiple, independent uncertainty components allows for a standardized estimation of ozone combined uncertainty. The approach implies the replacement of a single, complex ozone DIAL measurement model by the successive application of multiple, simpler measurement submodels. The sub-models consist of successive transformations to the raw lidar signals (e.g., saturation correction, background noise extraction, vertical filtering, see Sect. 3). At each sub-model level, standard uncertainty is evaluated in parallel for each independent uncertainty source introduced at the current or previous sub-model level. The final process- 
ing stage consists of combining all independent components together to obtain the ozone combined standard uncertainty.

\section{Proposed measurement model for the NDACC ozone DIAL}

In this section, a standardized measurement model for the retrieval of tropospheric and stratospheric ozone using the DIAL technique is constructed so that each input quantity introduced at one stage of the model is independent of the others.

\subsection{Lidar equation}

To retrieve an ozone profile in the troposphere or stratosphere using the DIAL technique, we start from the Lidar Equation (e.g., Hinkley, 1976; Weitkamp, 2005). This equation in its most compressed form describes the emission of light by a laser source, its backscatter at altitude $z$, its extinction and scattering along its path up and back, and its collection back on a detector:

$P\left(z, \lambda_{\mathrm{E}}, \lambda_{\mathrm{R}}\right)=$

$P_{\mathrm{L}}\left(\lambda_{\mathrm{E}}\right) \frac{\eta\left(z, \lambda_{\mathrm{R}}\right) \delta z}{\left(z-z_{\mathrm{L}}\right)^{2}} \tau_{\mathrm{UP}}\left(z, \lambda_{\mathrm{E}}\right) \beta\left(z, \lambda_{\mathrm{E}}, \lambda_{\mathrm{R}}\right) \tau_{\mathrm{DOWN}}\left(z, \lambda_{\mathrm{R}}\right)$,

where

- $\lambda_{\mathrm{E}}$ is the laser emission wavelength and $\lambda_{\mathrm{R}}$ is the receiver detection wavelength;

- $P$ is the total number of photons collected at wavelength $\lambda_{\mathrm{R}}$ on the lidar detector surface;

- $\delta z$ is the thickness of the backscattering layer sounded during the time interval $\delta t(\delta z=c \delta t / 2$, where $c$ is the speed of light);

- $P_{\mathrm{L}}$ is the number of photons emitted at the emission wavelength $\lambda_{\mathrm{E}}$;

- $\eta$ is the optical efficiency of the receiving channel, including optical and spectral transmittance and geometric obstruction;

- $z$ is the altitude of the backscattering layer;

$-z_{\mathrm{L}}$ is the altitude of the lidar (laser and receiver assumed to be at the same altitude);

- $\beta$ is the total backscatter coefficient (including particulate $\beta_{\mathrm{P}}$ and molecular $\beta_{\mathrm{M}}$ backscatter);

- $\tau_{\mathrm{UP}}$ is the optical thickness integrated along the outgoing beam path between the lidar and the scattering altitude $z$, and is defined as

$\tau_{\mathrm{UP}}(z)=\exp$

$\left[-\int_{z \mathrm{~L}}^{z}\left(\sigma_{\mathrm{M}}\left(\lambda_{\mathrm{E}}\right) N_{\mathrm{a}}\left(z^{\prime}\right)+\alpha_{\mathrm{P}}\left(z^{\prime}, \lambda_{\mathrm{E}}\right)+\sum_{i} \sigma_{i}\left(z^{\prime}, \lambda_{\mathrm{E}}\right) N_{i}\left(z^{\prime}\right)\right) \mathrm{d} z^{\prime}\right] ;$
- $\tau_{\text {DOWN }}$ is the optical thickness integrated along the returning beam path between the scattering altitude $z$ and the lidar receiver, and is defined as

$\tau_{\text {DOWN }}(z)=\exp$

$\left[-\int_{z \mathrm{~L}}^{z}\left(\sigma_{\mathrm{M}}\left(\lambda_{\mathrm{R}}\right) N_{\mathrm{a}}\left(z^{\prime}\right)+\alpha_{\mathrm{P}}\left(z^{\prime}, \lambda_{\mathrm{R}}\right)+\sum_{i} \sigma_{i}\left(z^{\prime}, \lambda_{\mathrm{R}}\right) N_{i}\left(z^{\prime}\right)\right) \mathrm{d} z^{\prime}\right]$

where $\sigma_{\mathrm{M}}$ is the molecular extinction cross section due to Rayleigh scattering (Strutt, 1899) (hereafter called "Rayleigh cross section" for brevity), $N_{\mathrm{a}}$ is the air number density, $\alpha_{\mathrm{P}}$ is the particulate extinction coefficient, $\sigma_{i}$ is the absorption cross section of absorbing constituent $i$, and $N_{i}$ is the number density of absorbing constituent $i$. For the altitude range of interest of the ozone DIAL measurements, the Rayleigh cross sections can be considered constant with altitude, and therefore depend only on wavelength. The absorption cross sections, however, are in most cases temperaturedependent, and should be taken as a function of both altitude and wavelength. Ozone number density is retrieved by reverting Eq. (9) with respect to the absorption term $\sigma_{i} N_{i}$.

\subsection{The DIAL equation}

In the DIAL technique we consider the lidar signals measured at two different wavelengths, the light at one wavelength being more absorbed by the target species (here, ozone) than the light at the other wavelength (Mégie et al., 1977). Using the notation ON for the most absorbed wavelength, and OFF for the least absorbed wavelength, Eq. (9) can be rewritten for each of the emitted wavelength:

$P_{\mathrm{ON}}(z)=$

$P_{\mathrm{L}}\left(\lambda_{1}\right) \frac{\eta_{\mathrm{ON}}(z) \delta z}{\left(z-z_{\mathrm{L}}\right)^{2}} \tau_{\mathrm{UP}}\left(z, \lambda_{1}\right) \beta\left(z, \lambda_{1}, \lambda_{2}\right) \tau_{\mathrm{DOWN}}\left(z, \lambda_{2}\right)$

$P_{\mathrm{OFF}}(z)=$

$P_{\mathrm{L}}\left(\lambda_{3}\right) \frac{\eta_{\mathrm{OFF}}(z) \delta z}{\left(z-z_{\mathrm{L}}\right)^{2}} \tau_{\mathrm{UP}}\left(z, \lambda_{3}\right) \beta\left(z, \lambda_{3}, \lambda_{4}\right) \tau_{\mathrm{DOWN}}\left(z, \lambda_{4}\right)$.

The emitted and received wavelength subscripts have been modified as follows:

$-\lambda_{1}$ and $\lambda_{2}$ are the emitted and received "ON" wavelengths respectively;

$-\lambda_{3}$ and $\lambda_{4}$ are the emitted and received "OFF" wavelengths respectively.

To obtain ozone number density $N_{\mathrm{O}_{3}}$, Eqs. (12)-(13) are reverted by taking the vertical derivative of the logarithm of the lidar signals measured at the ON and OFF wavelengths 
(Mégie et al., 1977):

$$
\begin{aligned}
& N_{\mathrm{O}_{3}}(z)=\frac{1}{\Delta \sigma_{\mathrm{O}_{3}}(z)} \\
& {\left[\frac{\partial}{\partial z}\left(\ln \frac{P_{\mathrm{OFF}}(z)}{P_{\mathrm{ON}}(z)}\right)-\Delta \sigma_{\mathrm{M}} N_{\mathrm{a}}(z)-\left(\sum_{\mathrm{ig}} \Delta \sigma_{\mathrm{ig}}(z) N_{\mathrm{ig}}(z)\right)\right.} \\
& \left.\quad-\Delta \alpha_{\mathrm{P}}(z)+\Lambda \eta(z)+\Lambda \beta(z)\right]
\end{aligned}
$$

The ozone absorption cross section differential $\Delta \sigma_{\mathrm{O}_{3}}$ is given by

$\Delta \sigma_{\mathrm{O}_{3}}(z)=\sigma_{\mathrm{O}_{3}}\left(z, \lambda_{1}\right)+\sigma_{\mathrm{O}_{3}}\left(z, \lambda_{2}\right)-\sigma_{\mathrm{O}_{3}}\left(z, \lambda_{3}\right)-\sigma_{\mathrm{O}_{3}}\left(z, \lambda_{4}\right)$.

$P_{\mathrm{ON}}$ and $P_{\mathrm{OFF}}$ are the number of photons collected on the detectors of the "ON" and "OFF" channels respectively.

For elastic (Rayleigh) scattering, the emitted and received wavelengths are identical, yielding $\lambda_{1}=\lambda_{2}$ and $\lambda_{3}=\lambda_{4}$. For inelastic scattering, the emitted and received wavelengths are different, and all four terms (two terms up and two terms down) are different (McGee et al., 1993). A list of most commonly used DIAL wavelength pairs for the measurement of stratospheric and tropospheric ozone is presented in Table 2 (see also Papayannis et al., 1990; Bösenberg, 1997).

$\Delta \sigma_{\mathrm{M}}$ is the Rayleigh cross section differential between the $\mathrm{ON}$ and OFF wavelengths computed along the beam path up to altitude $z$ and back:

$\Delta \sigma_{M}=\sigma_{M}\left(\lambda_{1}\right)+\sigma_{M}\left(\lambda_{2}\right)-\sigma_{M}\left(\lambda_{3}\right)-\sigma_{M}\left(\lambda_{4}\right)$.

$N_{\text {ig }}$ is the number density of absorbing constituent ig, and $\Delta \sigma_{\text {ig }}$ is the absorption cross section differential of constituent ig along the beam path up to altitude $z$ and back, and defined as

$\Delta \sigma_{\mathrm{ig}}(z)=\sigma_{\mathrm{ig}}\left(z, \lambda_{1}\right)+\sigma_{\mathrm{ig}}\left(z, \lambda_{2}\right)-\sigma_{\mathrm{ig}}\left(z, \lambda_{3}\right)-\sigma_{\mathrm{ig}}\left(z, \lambda_{4}\right)$.

$\Delta \alpha_{\mathrm{P}}$ is the extinction differential due to particles and computed along the beam path up to altitude $z$ and back:

$\Delta \alpha_{\mathrm{P}}(z)=\alpha_{\mathrm{P}}\left(z, \lambda_{1}\right)+\alpha_{\mathrm{P}}\left(z, \lambda_{2}\right)-\alpha_{\mathrm{P}}\left(z, \lambda_{3}\right)-\alpha_{\mathrm{P}}\left(z, \lambda_{4}\right)$.

This term depends strongly on the type of particulate matter, and is difficult to estimate for ozone lidar instruments that typically do not have dedicated aerosol channels (multiwavelength, polarization, etc.).

Finally, $\Lambda \eta$ and $\Lambda \beta$ are defined as

$\Lambda \eta(z)=\frac{\partial}{\partial z}\left(\ln \frac{\eta_{\mathrm{ON}}(z)}{\eta_{\mathrm{OFF}}(z)}\right)$

$\Lambda \beta(z)=\frac{\partial}{\partial z}\left(\ln \frac{\beta\left(z, \lambda_{1}, \lambda_{2}\right)}{\beta\left(z, \lambda_{3}, \lambda_{4}\right)}\right)$,

where $\eta_{\mathrm{ON}}$ and $\eta_{\mathrm{OFF}}$ are the optical efficiencies of the ON and OFF channels respectively, including optical and spectral transmittance and geometric obstruction.

\subsection{Actual ozone DIAL measurement model proposed for standardized use within NDACC}

The ozone DIAL measurement model depends on the choice of the theoretical equations used as well as their implementation to the real world, i.e., after considering all the caveats associated with the design, setup, and operation of an actual lidar instrument. Equation (14) relates to the expected number of photons reaching the lidar detectors $\left(P_{\mathrm{ON}}\right.$ and $\left.P_{\mathrm{OFF}}\right)$, not the actual raw lidar signals recorded in the data files by a real instrument. Its practical implementation for the retrieval of ozone therefore requires, on one hand the addition of several signal correction procedures and numerical transformations that depend on the instrumentation, and on the other hand, the development of approximations and/or the adoption of assumptions aimed to reduce the complexity of the measurement model.

In this context, uncertainty components associated with particulate extinction and backscatter $\left(\Delta \alpha_{\mathrm{P}}\right.$ and $\Lambda \beta$ terms in Eq. 14) will not be considered here. Their contribution is negligible in a cloud-free, "clean" atmosphere, which is mostly true for altitudes above $35 \mathrm{~km}$ (e.g., Godin-Beekmann et al., 2003), and in most cases of clear-sky, free-tropospheric ozone DIAL measurements for which the wavelength differential is small (Papayannis et al., 1990; McDermid et al., 2002). When present and non-negligible, the contribution of particulate extinction and backscatter is highly variable from site to site, time to time, and highly dependent on the nature and quantity of the particulate matter at the time of measurement. Rather different assessment methods exist (for a review, see e.g., Eisele and Trickl, 2005). Proposing a meaningful standardized treatment of this uncertainty component is therefore complex and beyond the scope of the present work. Similarly, uncertainty due to incomplete beam-telescope overlap correction $(\Lambda \eta$ term in Eq. 14) is instrument-dependent and often time-dependent for the same instrument. Therefore, no standardized formulation is provided here. However an example of treatment is provided in the ISSI team report (Leblanc et al., 2016a).

The detectors quantum efficiency and the effects of the data recorders (e.g., sky and electronic background noise, signal saturation) must be taken into account. Due to the diversity of lidar instrumentation, it is not possible to provide a single expression for the parametrization of these effects and obtain a unique, real-world version of Eq. (14) applicable to all systems. However, we will use standardized expressions that characterize the most commonly found cases, with the idea that the proposed approach for the propagation of uncertainty can be similarly applied to other cases.

Specifically, to transition from a theoretical to a real ozone DIAL measurement model, we will apply the following transformations.

1. For each lidar receiver channel, the actual raw signal $R$ recorded in the data files is represented by a vector of 
Table 2. List of most commonly used ozone DIAL wavelength pairs.

\begin{tabular}{|c|c|c|c|c|c|c|c|}
\hline $\begin{array}{l}\lambda_{1} \\
\mathrm{ON} \\
(\mathrm{nm})\end{array}$ & $\begin{array}{l}\lambda_{3} \\
\text { OFF } \\
(\mathrm{nm})\end{array}$ & $\begin{array}{l}\lambda_{2} \\
\mathrm{ON} \\
(\mathrm{nm})\end{array}$ & $\begin{array}{l}\lambda_{4} \\
\text { OFF } \\
(\mathrm{nm})\end{array}$ & $\begin{array}{l}\text { Backscatter } \\
\text { type }\end{array}$ & $\begin{array}{l}\text { Domain of } \\
\text { validity }\end{array}$ & $\begin{array}{l}\text { Light source details } \\
\left(\lambda_{1}\right)\end{array}$ & $\begin{array}{l}\text { Light source details } \\
\left(\lambda_{3}\right)\end{array}$ \\
\hline 266 & 289 & 266 & 289 & Rayleigh & Troposphere & $\begin{array}{l}\text { Quadrupled Nd:YAG } \\
266 \mathrm{~nm} \text { non-shifted }\end{array}$ & $\begin{array}{l}\text { Quadrupled Nd:YAG } \\
266 \text { nm Raman-shifted }\end{array}$ \\
\hline 277 & 291 & 277 & 291 & Rayleigh & Troposphere & $\begin{array}{l}\text { Excimer KrFl } \\
248 \text { nm Raman-shifted }\end{array}$ & $\begin{array}{l}\text { Excimer KrFl } \\
248 \text { nm Raman-shifted }\end{array}$ \\
\hline 277 & 313 & 277 & 313 & Rayleigh & Troposphere & $\begin{array}{l}\text { Excimer KrFl } \\
248 \text { nm Raman-shifted }\end{array}$ & $\begin{array}{l}\text { Excimer KrFl } \\
248 \mathrm{~nm} \text { Raman-shifted }\end{array}$ \\
\hline 287 & 294 & 287 & 294 & Rayleigh & Troposphere & $\begin{array}{l}\text { Ce:LiCAF tunable } \\
263 \mathrm{~nm} \text { tuned }\end{array}$ & $\begin{array}{l}\text { Ce:LiCAF tunable } \\
263 \mathrm{~nm} \text { tuned }\end{array}$ \\
\hline 289 & 299 & 289 & 299 & Rayleigh & Troposphere & $\begin{array}{l}\text { Quadrupled Nd:YAG } \\
266 \text { nm Raman-shifted }\end{array}$ & $\begin{array}{l}\text { Quadrupled Nd:YAG } \\
266 \text { nm Raman-shifted }\end{array}$ \\
\hline 299 & 316 & 299 & 316 & Rayleigh & Troposphere & $\begin{array}{l}\text { Quadrupled Nd:YAG } \\
266 \text { nm Raman-shifted }\end{array}$ & $\begin{array}{l}\text { Quadrupled Nd:YAG } \\
266 \text { nm Raman-shifted }\end{array}$ \\
\hline 308 & 353 & 308 & 353 & Rayleigh & Stratosphere & $\begin{array}{l}\text { Excimer } \mathrm{XeCl} \\
308 \mathrm{~nm} \text { non-shifted }\end{array}$ & $\begin{array}{l}\text { Excimer XeCl } \\
308 \text { nm Raman-shifted }\end{array}$ \\
\hline 308 & 355 & 308 & 355 & Rayleigh & Stratosphere & $\begin{array}{l}\text { Excimer } \mathrm{XeCl} \\
308 \mathrm{~nm} \text { non-shifted }\end{array}$ & $\begin{array}{l}\text { Nd:YAG tripled } \\
355 \mathrm{~nm} \text { non-shifted }\end{array}$ \\
\hline 308 & 353 & 332 & 385 & $\mathrm{~N}_{2}$ Raman & Stratosphere & $\begin{array}{l}\text { Excimer } \mathrm{XeCl} \\
308 \mathrm{~nm} \text { non-shifted }\end{array}$ & $\begin{array}{l}\text { Excimer XeCl } \\
308 \mathrm{~nm} \text { Raman-shifted }\end{array}$ \\
\hline 308 & 355 & 332 & 387 & $\mathrm{~N}_{2}$ Raman & Stratosphere & $\begin{array}{l}\text { Excimer } \mathrm{XeCl} \\
308 \mathrm{~nm} \text { non-shifted }\end{array}$ & $\begin{array}{l}\text { Nd:YAG tripled } \\
355 \mathrm{~nm} \text { non-shifted }\end{array}$ \\
\hline
\end{tabular}

discretized values rather than a continuous function of altitude range:

$z \rightarrow z(k)$ and $R(z) \rightarrow R(k)$ for $k=1, n k$

2. The actual raw signal recorded the data files is a combination of laser light backscattered in the atmosphere, sky background light that can be parametrized by a constant offset, and noise generated within the electronics (dark current and possibly signal-induced noise) that can be parametrized by a linear or nonlinear function of time, i.e., altitude range.

3. Only channels operating in photon-counting mode are considered hereafter. For analog channels, uncertainty due to analog-to-digital signal conversion needs to be estimated. This estimation is highly instrumentdependent, and no meaningful standardized recommendations can therefore be provided. However, an example of the treatment of the analog detection uncertainty is provided for reference in the ISSI team report (Leblanc et al., 2016a).

4. In photon-counting detection mode, the recorded signals result from nonlinear transfer of the detected signals due to the inability of the counting electronics to temporally discriminate a very large number of photoncounts reaching the detector ("pulse pile-up" effect resulting in signal saturation) (e.g., Müller, 1973; Donovan et al., 1993). In the present work, we consider the most frequent case of non-paralyzable photon-counting systems (i.e., using "non-extended dead time", Müller, 1973), which allows for an analytical correction of the pulse pile-up effect.

If $B$ is the sum of sky and electronic background noise, $\tau$ is the photon-counting hardware dead time characterizing the pulse pile-up effect, $c$ the speed of light, and $L$ the number of laser pulses for which the signal was actually recorded in the data files, the photon counts reaching the detectors $P$ can be expressed as a function of the discretized raw signal $R$ recorded in the data files at altitude $z(k)$ for the ON and OFF channels:

$$
\begin{aligned}
& P_{\mathrm{ON}}(k)=\frac{R_{\mathrm{ON}}(k)}{1-\tau_{\mathrm{ON}} \frac{c}{2 \delta z L} R_{\mathrm{ON}}(k)}-B_{\mathrm{ON}}(k) \\
& P_{\mathrm{OFF}}(k)=\frac{R_{\mathrm{OFF}}(k)}{1-\tau_{\mathrm{OFF}} \frac{c}{2 \delta z L} R_{\mathrm{OFF}}(k)}-B_{\mathrm{OFF}}(k) .
\end{aligned}
$$

5. The ozone DIAL measurement includes detection noise, and it is desirable to filter this noise whenever it is expected to impact the retrieved product. The filtering process impacts the propagation of uncertainties, and therefore should be included in the measurement model. For each individual altitude $z(k)$, the filtering process consists of convolving a set of filter coefficients $c_{\mathrm{p}}$ with an unsmoothed signal $s_{\mathrm{u}}$ to obtain a smoothed signal $s_{\mathrm{m}}$ :

$s_{\mathrm{m}}(k)=\sum_{p=-n}^{n} c_{\mathrm{p}}(k) s_{\mathrm{u}}(k+p)$. 
In the case of ozone DIAL, this smoothing can occur at various stages of the retrieval, including signal processing (e.g., $s=R$ or $s=P)$, after ozone is computed $\left(s=N_{\mathrm{O}_{3}}\right)$, or at the time of differentiation. In this latter case, when computing the derivative of the logarithm of the ratio of the discretized signals at the ON and OFF wavelengths, a three-point central difference is typically used if no smoothing is needed. Using a three-point central difference scheme is equivalent to using Eq. (23) with three coefficients of value $-0.5,0$, and 0.5 . If smoothing is required in addition to differentiation, smooth-derivative filters can be used by using Eq. (23) with more than three antisymmetric coefficients $\left(c_{\mathrm{p}}=-c_{-\mathrm{p}}\right.$ for all $p$, and $\left.c_{0}=0\right)$. Because of its analytical convenience, in the rest of this work, the differentiation term in Eq. (14) will be numerically expressed using the convolution form of Eq. (23):

$$
\begin{aligned}
& \frac{\partial}{\partial z}\left(\ln \frac{P_{\mathrm{OFF}}(z)}{P_{\mathrm{ON}}(z)}\right) \rightarrow S(k)= \\
& \frac{1}{\delta z} \sum_{p=-n}^{n} c_{\mathrm{p}}(k) \ln \left(\frac{P_{\mathrm{ON}}(k+p)}{P_{\mathrm{OFF}}(k+p)}\right), \\
& \text { with } c_{\mathrm{p}}(k)=-c_{-p}(k) \text { for all } p .
\end{aligned}
$$

Equation (24) implies the use of an odd number of coefficients. Alternate numerical differentiation schemes such as a two-point difference can also be used, but the output vertical grid will end up shifted by half a bin with respect to the original grid. There is little advantage of using this method as all the other terms in Eq. (14) must be re-interpolated onto the shifted grid. A theoretical review of digital filtering and recommendations for the use of standardized vertical resolution definitions are provided in our Part 1 (Leblanc et al., 2016a).

Given the above numerical signal transformations, a discretized version of Eq. (14) can now be formulated as follows:

$$
\begin{aligned}
& N_{\mathrm{O}_{3}}(k)= \\
& \frac{1}{\Delta \sigma_{\mathrm{O}_{3}}(k)}\left[S(k)-\Delta \sigma_{\mathrm{M}} N_{\mathrm{a}}(k)-\left(\sum_{\mathrm{ig}} \Delta \sigma_{\mathrm{ig}}(k) N_{\mathrm{ig}}(k)\right)\right] .
\end{aligned}
$$

A product commonly derived from the lidar-measured ozone number density is ozone mixing ratio $q_{\mathrm{O}_{3}}$. The transformation simply consists of dividing the lidar-measured ozone number density by the "best available" ancillary air number density:

$$
\begin{aligned}
& q_{\mathrm{O}_{3}}(k)= \\
& \frac{1}{\Delta \sigma_{\mathrm{O}_{3}}(k)}\left[\frac{S(k)}{N_{\mathrm{a}}(k)}-\Delta \sigma_{\mathrm{M}}-\left(\sum_{\mathrm{ig}} \Delta \sigma_{\mathrm{ig}}(k) q_{\mathrm{ig}}(k)\right)\right] .
\end{aligned}
$$

Most mixing ratio uncertainty components can be directly inferred from their number density counterpart. However, the known correlation between certain input quantities and air number density led us to provide explicitly, for each component, a formulation of both the number density and mixing ratio uncertainties. Specifically, in Eq. (25), we have used the absorbing constituents' mixing ratio $q_{\text {ig }}$ instead of the number density $N_{\mathrm{ig}}$. In the rest of this work it will be assumed that either the mixing ratio or the number density, whichever quantity is independent of the air number density, should be used as input quantity. In particular, we will address the case of molecular oxygen $\left(\mathrm{ig}=\mathrm{O}_{2}\right.$ ) number density, which is fully correlated with air number density via its constant mixing ratio $\left(q_{\mathrm{O}_{2}} \approx 0.209\right)$.

Another important component of our ozone DIAL measurement model is the expression of the cross section differential (Eqs. 15-17), which has the following numerical implementation:

$$
\Delta \sigma_{X}(k)=\sigma_{X_{-} 1}(k)+\sigma_{X_{-}}(k)-\sigma_{X_{-} 3}(k)-\sigma_{X_{-} 4}(k) .
$$

The generic subscript $X$ stands for $\mathrm{O}_{3}$ for ozone absorption cross sections, $M$ for Rayleigh cross sections, and ig for absorption cross sections of the interfering gases. The subscripts 1 through 4 have the same meaning as in Eqs. (15)(17).

Equations (21)-(26) constitute our proposed standardized ozone DIAL measurement model. This model represents the set of equations adopted to estimate the standardized ozone uncertainty budget. The output quantity is ozone number density (left-hand side of Eq. 24) or mixing ratio (left-hand side of Eq. 25), while the input quantities are all the variables introduced on the right-hand side of Eqs. (21)-(22) and Eqs. (24)-(26). The input quantities' true values are unknown. These quantities' standard uncertainty must be introduced, then propagated through the ozone DIAL measurement model, and then combined to produce an ozone combined standard uncertainty profile.

Based on Eqs. (21)-(22), the instrumentation-related input quantities to consider in the NDACC-lidar standardized ozone uncertainty budget are the following:

1. detection noise inherent to photon-counting signal detection;

2. saturation (pulse pile-up) correction parameters (typically, photon counters' dead time $\tau$ );

3. background noise extraction parameters (typically, fitting parameters for function $B$ ).

Based on Eqs. (24)-(25), the additional input quantities to consider in the NDACC-lidar standardized ozone uncertainty budget are the following:

4. ozone absorption cross sections differential $\Delta \sigma_{\mathrm{O}_{3}}$;

5. Rayleigh extinction cross sections differential $\Delta \sigma_{\mathrm{M}}$;

6. ancillary air number density profile $N_{\mathrm{a}}$ (or temperature $T_{\mathrm{a}}$ and pressure $p_{\mathrm{a}}$ profiles); 
7. absorption cross sections differential for the interfering gases $\Delta \sigma_{\text {ig }}$

8. Number density profiles $N_{\text {ig }}$ (or mixing ratio profile $q_{\mathrm{ig}}$ ) of the interfering species.

The interfering gases (ig) to consider in practice are $\mathrm{NO}_{2}$, $\mathrm{SO}_{2}$, and $\mathrm{O}_{2}$. Because of either very low concentrations or very low values of their absorption cross section differentials for the ON and OFF wavelengths typically used for stratospheric and tropospheric ozone DIAL, no other atmospheric gases or molecules are expected to interfere with the ozone DIAL retrieval. In addition, $\mathrm{NO}_{2}$ and $\mathrm{SO}_{2}$ absorption is usually negligible in the stratospheric ozone retrieval (0.1-1\% ozone error or less if neglected), as well as most cases of tropospheric ozone retrieval. However it is included here to account for the potentially non-negligible effect of a heavily polluted boundary layer, or potentially heavy volcanic aerosols loading conditions (Godin-Beekmann et al., 2003). The absorption by $\mathrm{O}_{2}$ should be considered only if any of the detection wavelengths is shorter than $294 \mathrm{~nm}$ as the interfering absorption relates to the Herzberg continuum, Herzberg and Wulf bands (Jenouvrier et al., 1999; Fally et al., 2000; Merienne et al., 2001). As already mentioned, the $\mathrm{O}_{2}$ number density $N_{\mathrm{O}_{2}}$ is assumed to be directly proportional to air number density $N_{\mathrm{a}}$ (constant mixing ratio), and therefore should not be considered as an input quantity.

In order to limit the complexity of the standardization process, the contribution of uncertainty associated with the fundamental physical constants is treated differently from that of the other input quantities. Just like we did for standard uncertainty, we refer here to an internationally recognized and traceable standard for our recommendations on the use of physical constants, namely the International Council for Science (ICSU) Committee on Data for Science and Technology (CODATA, http://www.codata.org/), endorsed by the BIPM (Mohr et al., 2008). Within the CODATA, the Task Group on Fundamental Constants (TGFC) provides the scientific and technological communities a self-consistent set of internationally recommended values of the basic constants and conversion factors of physics and chemistry that can be found here: http://physics.nist.gov/cuu/Constants/index.html.

Our proposed approach ensures that there is indeed no propagation of uncertainty for fundamental physical constants. To do so, we truncate the CODATAreported values to the decimal level where the CODATAreported uncertainty no longer affects rounding. For example, the Boltzmann constant value reported by the CODATA is $1.3806488 \times 10^{-23} \mathrm{JK}^{-1}$ with an uncertainty of $0.0000013 \times 10^{-23} \mathrm{JK}^{-1}$. If we truncate to the value of $1.38065 \times 10^{-23} \mathrm{JK}^{-1}$, adding or subtracting its uncertainty does not modify the truncated value, and we therefore consider this value as "exact" (i.e., no uncertainty to be propagated). However, in the unlikely case that the uncertainty of a fundamental constant is of a similar order of magnitude as the uncertainty components identified in the previous para- graphs, this fundamental constant must be treated similarly to any other input quantities introduced in the measurement model; i.e., its uncertainty should be taken into account and propagated.

\section{Proposed formulation for the propagation of uncertainty through the ozone DIAL retrieval}

The expressions for the propagation of uncertainty presented in this section are derived directly from the equations of our proposed standardized ozone DIAL measurement model (previous section), and by systematically applying the law of variance propagation described in Sect. 2 (Eq. 4). For clarity, throughout this section we will use the following variable naming convention: each newly introduced output quantity $Y$ will have one or several uncertainty components $u_{Y(X i)}$ owing to the uncertainty source $X_{i}$. In addition, the subscripts $\mathrm{ON}$ and OFF will be added when the quantity or its uncertainty is computed from the signals recorded in the $\mathrm{ON}$ or OFF channels respectively, as described in the previous section. Each introduced component $u_{Y(X i)}$ is assumed independent of the other components $u_{Y(X j)}(j \neq i)$, which allows a full description of their covariance matrix in altitude and across receiver channels throughout the entire signal processing. Additional details can be found in the ISSI team report (Leblanc et al., 2016a).

\subsection{Uncertainty owing to detection noise}

Random noise is inherently present in any physical system performing an actual measurement. In the case of the ozone DIAL measurement, it is introduced at the detection level, where the signal is recorded in the data files (raw signal $R$ ). The associated detection noise uncertainty is derived from Poisson statistics associated with the probability of detection of a repeated random event (Type A uncertainty estimation) (e.g., Measures, 1984). Using the subscript (DET) for detection noise, the uncertainty in the raw signal $R$ owing to detection noise can be expressed independently for each altitude bin $k$ and for each of the ON and OFF receiver channels as

$u_{\mathrm{RON}(\mathrm{DET})}(k)=\sqrt{R_{\mathrm{ON}}(k)}$
$u_{\mathrm{ROFF}(\mathrm{DET})}(k)=\sqrt{R_{\mathrm{OFF}}(k)}$.

This uncertainty component reflects purely random effects, and therefore implies no correlation between any of the samples considered. It is therefore propagated to ozone number density by consistently adding in quadrature the uncertainties of the individual samples used in the signal transformations. If we assume a non-paralyzable photon-counting hardware, it is propagated to the saturation and background noisecorrected signal $P$ by applying Eq. (4) to the signal transfor- 
mation equations (Eqs. 21-22) with no covariance terms:

$$
\begin{aligned}
& u_{\mathrm{PON}(\mathrm{DET})}(k)=\left(\frac{P_{\mathrm{ON}}(k)}{R_{\mathrm{ON}}(k)}\right)^{2} \sqrt{R_{\mathrm{ON}}(k)} \\
& u_{\mathrm{POFF}(\mathrm{DET})}(k)=\left(\frac{P_{\mathrm{OFF}}(k)}{R_{\mathrm{OFF}}(k)}\right)^{2} \sqrt{R_{\mathrm{OFF}}(k)} .
\end{aligned}
$$

It is finally propagated to the retrieved ozone number density $N_{\mathrm{O}_{3}}$ and mixing ratio $q_{\mathrm{O}_{3}}$ by applying Eq. (4) to the signal transformation equations (Eqs. 24-26) with no covariance terms:

$u_{\mathrm{NO}_{3}(\mathrm{DET})}(k)=\frac{1}{\left|\Delta \sigma_{\mathrm{O}_{3}}(k)\right| \delta z}$

$$
\sqrt{\sum_{p=-n}^{n} c_{\mathrm{p}}^{2}(k)\left(\left(\frac{u_{\mathrm{PON}(\mathrm{DET})}(k+p)}{P_{\mathrm{ON}}(k+p)}\right)^{2}+\left(\frac{u_{\mathrm{POFF}(\mathrm{DET})}(k+p)}{P_{\mathrm{OFF}}(k+p)}\right)^{2}\right)}
$$

$u_{q \mathrm{O}_{3}(\mathrm{DET})}(k)=\frac{1}{N_{\mathrm{a}}(k)\left|\Delta \sigma_{\mathrm{O}_{3}}(k)\right| \delta z}$

$$
\sqrt{\sum_{p=-n}^{n} c_{\mathrm{p}}^{2}(k)\left(\left(\frac{u_{\mathrm{PON}(\mathrm{DET})}(k+p)}{P_{\mathrm{ON}}(k+p)}\right)^{2}+\left(\frac{u_{\mathrm{POFF}(\mathrm{DET})}(k+p)}{P_{\mathrm{OFF}}(k+p)}\right)^{2}\right)} .
$$

The order of magnitude of this uncertainty component depends on many factors including instrumentation, laser power, optical and electronic efficiencies, ozone abundance, integration time, and vertical resolution. Figure 1 shows this order of magnitude for typical NDACC stratospheric ozone DIAL systems. Depending on the lidar system considered, the Rayleigh backscatter channels $(308 / 355 \mathrm{~nm})$ may be optimized to measure in the upper stratosphere (high-intensity channels) or the lower stratosphere (low-intensity channels), or both. The results are presented as generically as possible in order to infer the order of magnitude of this uncertainty component for a wide range of system performances. Figure 1 shows cases representative of signals reaching a count rate of $1 \mathrm{MHz}$ at six different altitudes $(40,35,30,24,20$ and $15 \mathrm{~km}$ ) for both the ON and OFF channels. In addition to six Rayleigh backscatter DIAL pairs (solid curves, solid circles), one Raman backscatter pair $(332 / 387 \mathrm{~nm})$ is shown (open circles, dashed curves) with a typical counting rate of $1 \mathrm{MHz}$ at $24 \mathrm{~km}$ for both the ON and OFF channels. The uncertainty values reflect a typical midlatitude climatological profile with ozone number densities increasing from $10^{18}$ to $5.10^{18}$ molec $\mathrm{m}^{-3}$ between $10 \mathrm{~km}$ and $24 \mathrm{~km}$, and then decreasing from $5.10^{18}$ to $10^{17}$ molec m${ }^{-3}$ from 24 to $50 \mathrm{~km}$ (which corresponds to a 8 ppmv mixing ratio peak at $34 \mathrm{~km}$ ). All computations were made assuming 120 min lidar integration time, and constant $1 \mathrm{~km}$ vertical resolution following the standardized definition presented in our companion paper (Part 1, Leblanc et al., 2016). Shorter integration times or higher vertical resolutions would shift all curves towards the right (larger detection noise uncertainty), while longer integration times or degraded vertical resolutions would shift all curves toward the left (smaller detection noise uncertainty).

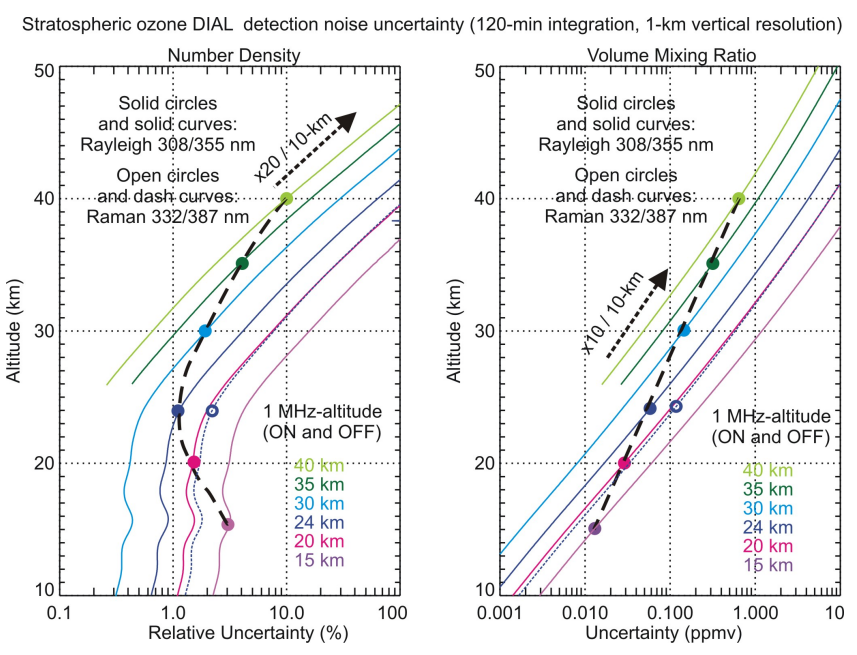

Figure 1. Ozone number density relative uncertainty (left) and ozone mixing ratio uncertainty (right) owing to detection noise for stratospheric ozone DIAL systems of varying performance, and for a $120 \mathrm{~min}$ integration time and $1 \mathrm{~km}$ vertical resolution. The systems' performance is measured as the altitude of $1 \mathrm{MHz}$ count rate for both the ON and OFF channels signals. See text for details.

For the ozone number density relative uncertainty (left plot), the main feature is a nearly constant magnitude between 10 and $24 \mathrm{~km}$ associated with the gain of sensitivity resulting from the increase of ozone number density in the lower stratosphere, which compensates the loss of backscattered signal. Above $24 \mathrm{~km}$, the exponential increase reflects the combined effect of the decrease in ozone number density and backscatter signal. In this latter region, the relative uncertainty increases by a factor of 20 every $10 \mathrm{~km}$, as indicated by the black arrow. The thick long-dash black curve indicates the approximate location of the $1 \mathrm{MHz}$ count rate as a function of altitude. Using this curve, the ozone relative uncertainty owing to detection noise can be estimated for any stratospheric ozone DIAL by simply starting from the known altitude of the $1 \mathrm{MHz}$ count rate (located somewhere on the black curve), and then drawing a curve parallel to the existing colored curves. Note the factor of 2 between the Rayleigh and Raman backscatter channels' relative uncertainty curves for the same signal magnitude (blue solid curve and blue dashed curve respectively). The difference is due to a reduced sensitivity of the less-absorbing, longer Raman-shifted wavelengths. In terms of ozone mixing ratio (right plot), uncertainty owing to detection noise increases exponentially with altitude, the magnitude being multiplied by a factor of 10 every $10 \mathrm{~km}$.

Figure 2 is similar to Fig. 1 but for typical tropospheric ozone DIAL systems. The uncertainty values shown correspond to a climatological ozone profile with number densities around $10^{18}$ molec $\mathrm{m}^{-3}$, i.e., $40-60 \mathrm{ppbv}$ between the ground and $10 \mathrm{~km}$ height. Because the 289/299 nm DIAL pair is currently the most commonly used across NDACC, three dif- 

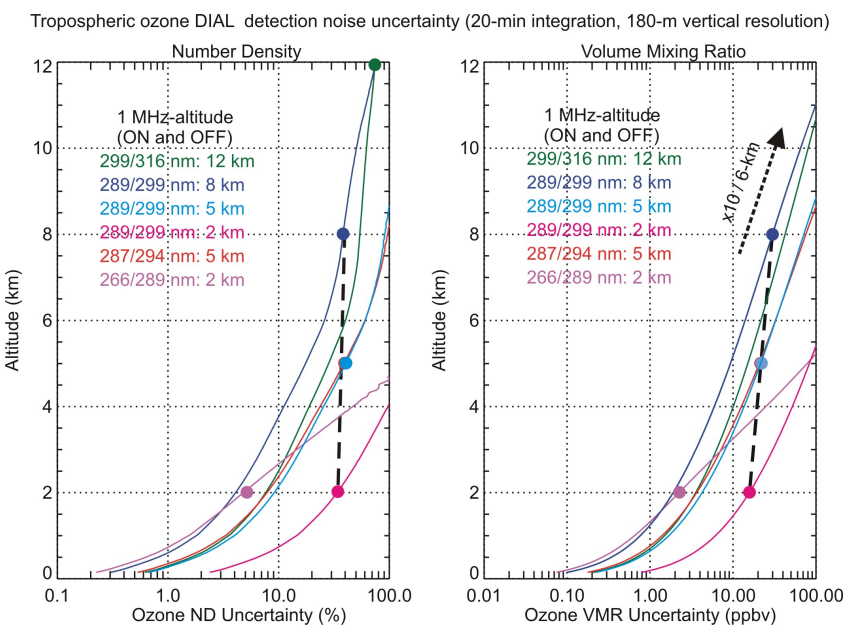

Figure 2. Same as Fig. 1, but for tropospheric ozone systems. This time, integration time is $20 \mathrm{~min}$ and vertical resolution is $180 \mathrm{~m}$. See text for details.

ferent altitudes of $1 \mathrm{MHz}$ count rate are shown for this pair. Three other pairs, namely 299/316, 287/294, and 266/289 nm are also shown at their typical magnitude $(1 \mathrm{MHz}$ count rate at 12,5 , and $2 \mathrm{~km}$ respectively). Not surprisingly, all $289 / 299 \mathrm{~nm}$ pairs show a similar uncertainty curve shape, and the uncertainty for the $266 / 289 \mathrm{~nm}$ increases at a much faster rate than the others due to the enhanced sensitivity and faster signal loss (large absorption).

\subsection{Uncertainty owing to saturation (pulse pile-up) correction}

This uncertainty component is introduced only for channels operating in photon-counting mode. If we consider a nonparalyzable counting hardware, the only input quantity to introduce is the hardware's dead time (sometimes called resolving time), which characterizes the speed of the counting electronics. The dead time $\tau$ and its uncertainty $u_{\tau}$ are generally among the technical specifications provided by the hardware manufacturer (Type-B estimation). The associated saturation correction uncertainty is derived by applying Eq. (4) to Eqs. (21)-(22). Using the subscript (SAT) for saturation, it can be expressed independently for the ON and OFF channels as

$$
\begin{aligned}
& u_{\mathrm{PON}(\mathrm{SAT})}(k)=\frac{c}{2 \delta z L} P_{\mathrm{ON}}^{2}(k) u_{\tau_{\mathrm{ON}}} \\
& u_{\mathrm{POFF}(\mathrm{SAT})}(k)=\frac{c}{2 \delta z L} P_{\mathrm{OFF}}^{2}(k) u_{\tau_{-} \mathrm{OFF}} .
\end{aligned}
$$

The saturation correction uncertainty needs to be propagated through Eqs. (24)-(26). According to Eqs. (21)-(22), the same dead-time value is used at all altitudes for a given channel. When vertically filtering the signal, the saturation correction uncertainty is therefore propagated, assuming full correlation between neighboring altitude samples. Applying verti- cal differentiation (Eq. 24) therefore results in a linear combination of the samples' uncertainties identical to that applied to the samples' values. However, when combining the $\mathrm{ON}$ and OFF channels, two instrumental configuration cases need to be considered.

1. If the photon-counting hardware of the $\mathrm{ON}$ and $\mathrm{OFF}$ channels is different, the channels can be considered independent and the saturation correction uncertainty can be propagated to the retrieved ozone number density and mixing ratio through the differentiation equation (Eq. 24), assuming no correlation between samples measured in the $\mathrm{ON}$ and OFF channels (no covariance terms), thus resulting in the following expressions:

$$
\begin{aligned}
& u_{\mathrm{NO}_{3}(\mathrm{SAT})}(k)= \\
& \frac{1}{\left|\Delta \sigma_{\mathrm{O}_{3}}(k)\right| \delta z} \sum_{p=-n}^{n} c_{\mathrm{p}}(k) \\
& \sqrt{\left(\left(\frac{u_{\mathrm{PON}(\mathrm{SAT})}(k+p)}{P_{\mathrm{ON}}(k+p)}\right)^{2}+\left(\frac{u_{\mathrm{POFF}(\mathrm{SAT})}(k+p)}{P_{\mathrm{OFF}}(k+p)}\right)^{2}\right)} \\
& u_{q \mathrm{O}_{3}(\mathrm{SAT})}(k)= \\
& \frac{1}{N_{\mathrm{a}}(k)\left|\Delta \sigma_{\mathrm{O}_{3}}(k)\right| \delta z} \sum_{p=-n}^{n} c_{\mathrm{p}}(k) \\
& \sqrt{\left(\left(\frac{u_{\mathrm{PON}(\mathrm{SAT})}(k+p)}{P_{\mathrm{ON}}(k+p)}\right)^{2}+\left(\frac{u_{\mathrm{POFF}(\mathrm{SAT})}(k+p)}{P_{\mathrm{OFF}}(k+p)}\right)^{2}\right)} .
\end{aligned}
$$

2. If the $\mathrm{ON}$ and $\mathrm{OFF}$ channels share the same hardware, the apparatus is considered identical for both channels, and the saturation correction uncertainty should therefore be propagated to the retrieved ozone number density and mixing ratio through the differentiation equation assuming full correlation between the samples measured by the $\mathrm{ON}$ and OFF channels, resulting in the following expressions:

$$
\begin{aligned}
& u_{\mathrm{NO}_{3}(\mathrm{SAT})}(k)=\frac{1}{\left|\Delta \sigma_{\mathrm{O}_{3}}(k)\right| \delta z} \sum_{p=-n}^{n} c_{\mathrm{p}}(k) \\
& \left|\frac{u_{\mathrm{PON}(\mathrm{SAT})}(k+p)}{P_{\mathrm{ON}}(k+p)}-\frac{u_{\mathrm{POFF}(\mathrm{SAT})}(k+p)}{P_{\mathrm{OFF}}(k+p)}\right| \\
& u_{q \mathrm{O}_{3}(\mathrm{SAT})}(k)=\frac{1}{N_{\mathrm{a}}(k)\left|\Delta \sigma_{\mathrm{O}_{3}}(k)\right| \delta z} \sum_{p=-n}^{n} c_{\mathrm{p}}(k) \\
& \left|\frac{u_{\mathrm{PON}(\mathrm{SAT})}(k+p)}{P_{\mathrm{ON}}(k+p)}-\frac{u_{\mathrm{POFF}(\mathrm{SAT})}(k+p)}{P_{\mathrm{OFF}}(k+p)}\right| .
\end{aligned}
$$

The order of magnitude of this uncertainty component depends mainly on signal magnitude with respect to the deadtime value, i.e., laser power and optical and electronic efficiencies, as well as on the dead-time uncertainty. Figure 3 

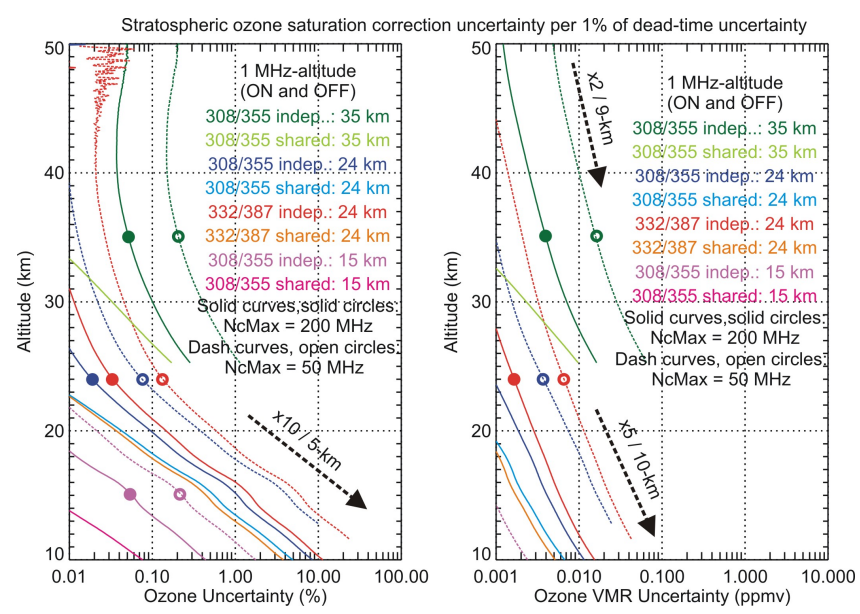

Figure 3. Ozone number density relative uncertainty (left) and ozone mixing ratio uncertainty (right) owing to saturation correction for stratospheric ozone DIAL systems of varying performance. The systems' performance is measured as the altitude of $1 \mathrm{MHz}$ count rate for both the ON and OFF channels signals. See text for details.

shows this order of magnitude for typical NDACC stratospheric ozone DIAL systems, and for each percent of deadtime uncertainty (i.e., if the dead-time uncertainty of a specific system is $5 \%$, then the actual ozone uncertainty estimates are 5 times larger than those plotted in Fig. 3). Several configuration cases are shown: signals with a count rate of $1 \mathrm{MHz}$ at three different altitudes $(35,24$, and $15 \mathrm{~km})$ for both the ON and OFF channels, for two different dead-time values $(1 / \tau=200$ and $50 \mathrm{MHz})$, and when using either two independent hardware devices (Eqs. 35-36) or sharing the same hardware (Eqs. 37-38). Below the ozone peak, relative uncertainty decreases by a factor of 10 every $5 \mathrm{~km}$, and mixing ratio uncertainty decreases by a factor of 5 every $10 \mathrm{~km}$. Above the ozone peak, relative uncertainty is nearly constant with altitude, and mixing ratio uncertainty decreases by a factor of 5 every $10 \mathrm{~km}$.

Figure 4 is similar to Fig. 3 but for typical tropospheric ozone DIAL systems. At an altitude range larger than $3 \mathrm{~km}$, the relative uncertainty is divided by 2 every $1 \mathrm{~km}$, while the mixing ratio uncertainty is divided by 3 every $2 \mathrm{~km}$. Values above $10 \%$ ( $6 \mathrm{ppbv}$ ) are found only at the very bottom of the profiles, when the signal dynamic range increases dramatically (near-range measurements).

\subsection{Uncertainty owing to background noise extraction}

At far range, backscattered signal is too weak to be detected and any nonzero signal reflects the presence of undesired skylight and/or electronic background noise. This noise is typically subtracted from the total signal by fitting the uppermost part of the lidar signal with a linear or nonlinear function of altitude $B$. A new uncertainty component associated with the noise fitting procedure must therefore be introduced.

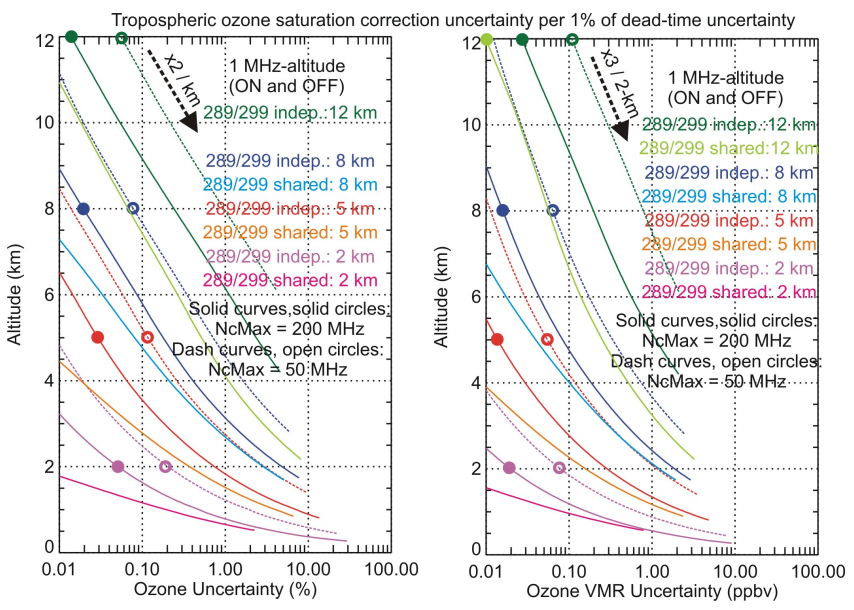

Figure 4. Same as Fig. 3, but for tropospheric ozone systems. See text for details.

Here we provide a detailed treatment for the simple case of a linear fit. It can be easily generalized to many other fitting functions. The linear fitting function takes the form:

$B(k)=b_{0}+b_{1} z(k)$

For many well-known fitting methods (e.g., least-squares), the fitting coefficients $b_{i}$ can be calculated analytically together with their uncertainty $u_{b i}$ and their correlation coefficient $r_{b i, b j}$ (Type A estimation) (Press et al., 1986). Using the subscript (BKG) for background noise, the background noise correction uncertainty is expressed independently for the ON and OFF channels by applying Eq. (4) to the signal transformation equations (Eqs. 21-22), and using the linear form of Eqs. (21)-(22), for $B$, we obtain

$u_{\mathrm{PON}(\mathrm{BKG})}(k)=$

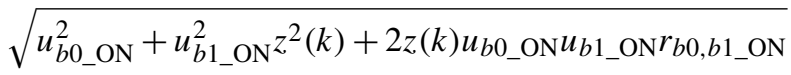

$u_{\mathrm{POFF}(\mathrm{BKG})}(k)=$

$\sqrt{u_{b 0 \_\mathrm{OFF}}^{2}+u_{b 1 \_\mathrm{OFF}}^{2} z^{2}(k)+2 z(k) u_{b 0 \_\mathrm{OFF}} u_{b 1 \_\mathrm{OFF}} r_{b 0, b 1 \_\mathrm{OFF}}}$.

The above two equations can be derived analytically for any fitting function for which the fitting method allows for the proper estimation of the fitting parameters' covariance matrix (e.g., least-squares and singular value decomposition).

Because of the nature of the background noise correction (parameters $b_{i}$ independent of altitude), the approach used for the propagation of saturation correction uncertainty can also be used for the propagation of background noise correction uncertainty. In other words, the following is true.

1. If the data acquisition hardware of the $\mathrm{ON}$ and $\mathrm{OFF}$ channels is different, the background noise correction uncertainty can be propagated assuming no correlation between the ON and OFF channels (no covariance 
terms):

$u_{\mathrm{NO}_{3}(\mathrm{BKG})}(k)=\frac{1}{\left|\Delta \sigma_{\mathrm{O}_{3}}(k)\right| \delta z} \sum_{p=-n}^{n} c_{\mathrm{p}}(k)$

$$
\begin{aligned}
& \sqrt{\left(\left(\frac{u_{\mathrm{PON}(\mathrm{BKG})}(k+p)}{P_{\mathrm{ON}}(k+p)}\right)^{2}+\left(\frac{u_{\mathrm{POFF}(\mathrm{BKG})}(k+p)}{P_{\mathrm{OFF}}(k+p)}\right)^{2}\right)} \\
& u_{q \mathrm{O}_{3}(\mathrm{BKG})}(k)=\frac{1}{N_{\mathrm{a}}(k)\left|\Delta \sigma_{\mathrm{O}_{3}}(k)\right| \delta z} \sum_{p=-n}^{n} c_{\mathrm{p}}(k) \\
& \sqrt{\left(\left(\frac{u_{\mathrm{PON}(\mathrm{BKG})}(k+p)}{P_{\mathrm{ON}}(k+p)}\right)^{2}+\left(\frac{u_{\mathrm{POFF}(\mathrm{BKG})}(k+p)}{P_{\mathrm{OFF}}(k+p)}\right)^{2}\right)} .
\end{aligned}
$$

2. If the $\mathrm{ON}$ and $\mathrm{OFF}$ channels share the same hardware, the background noise correction uncertainty can be propagated to the retrieved ozone number density and mixing ratio through the differentiation equation assuming full correlation between the ON and OFF channels:

$$
\begin{aligned}
& u_{\mathrm{NO}_{3}(\mathrm{BKG})}(k)=\frac{1}{\left|\Delta \sigma_{\mathrm{O}_{3}}(k)\right| \delta z} \sum_{p=-n}^{n} c_{\mathrm{p}}(k) \\
& \left|\frac{u_{\mathrm{PON}(\mathrm{BKG})}(k+p)}{P_{\mathrm{ON}}(k+p)}-\frac{u_{\mathrm{POFF}(\mathrm{BKG})}(k+p)}{P_{\mathrm{OFF}}(k+p)}\right| \\
& u_{q \mathrm{O}_{3}(\mathrm{BKG})}(k)=\frac{1}{N_{\mathrm{a}}(k)\left|\Delta \sigma_{\mathrm{O}_{3}}(k)\right| \delta z} \sum_{p=-n}^{n} c_{\mathrm{p}}(k) \\
& \left|\frac{u_{\mathrm{PON}(\mathrm{BKG})}(k+p)}{P_{\mathrm{ON}}(k+p)}-\frac{u_{\mathrm{POFF}(\mathrm{BKG})}(k+p)}{P_{\mathrm{OFF}}(k+p)}\right| .
\end{aligned}
$$

However, the above formulation is valid only if the response of the detector and counting chain is identical for the $\mathrm{ON}$ and OFF channels, which is not always the case even though the same hardware is being used.

The order of magnitude of the propagated ozone uncertainty owing to background noise correction depends on many factors, including the relative magnitude of the $\mathrm{ON}$ and OFF signals with respect to noise being subtracted, and the slope of the signal-induced noise if signal-induced noise is present. Figure 5 (respectively Fig. 6) shows one example of this magnitude and its change with altitude for stratospheric (respectively tropospheric) ozone DIAL pairs with a constant background noise extracted. In this case, the coefficient $b_{1}$ is set to zero, and the only uncertainty is that associated with the fitting parameter's uncertainty $u_{b 0}$. The rate at which uncertainty increases with altitude in this case is simply determined by the signal slope differential (for example, sharp increase for the tropospheric pair $266 / 289 \mathrm{~nm}$ compared to the pair 299/316 nm, as shown in Fig. 6).

The above case (constant noise) and the case of noise having a well-known, mild constant slope are the simplest cases to deal with, for which the only uncertainty component to consider is that owing to the fitting parameters. In the presence of non-negligible signal-induced noise, the slope of the

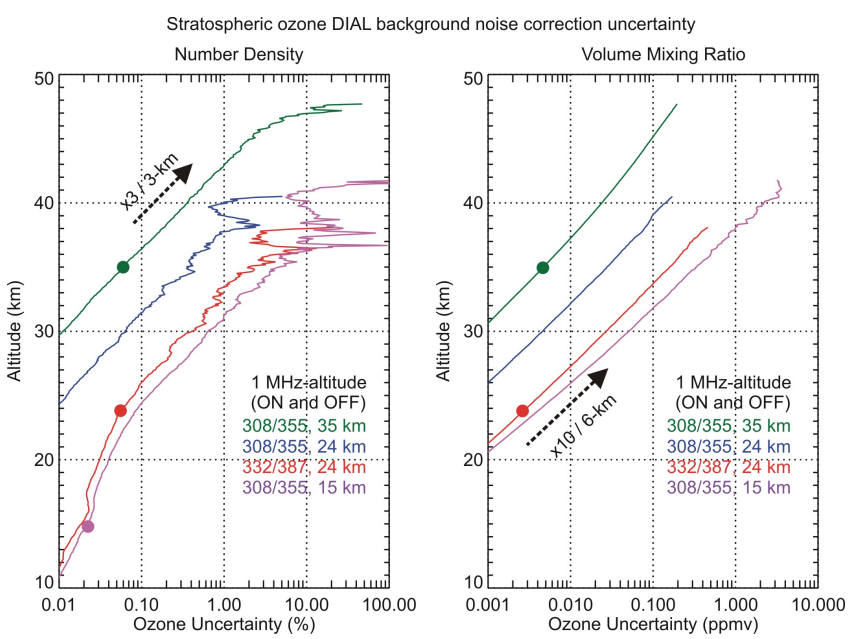

Figure 5. Ozone number density relative uncertainty (left) and ozone mixing ratio uncertainty (right) owing to background noise correction (linear fit) for stratospheric ozone DIAL systems of varying performance. The systems' performance is measured as the altitude of $1 \mathrm{MHz}$ count rate for both the $\mathrm{ON}$ and OFF channels signals, using typical nighttime background noise conditions. See text for details.
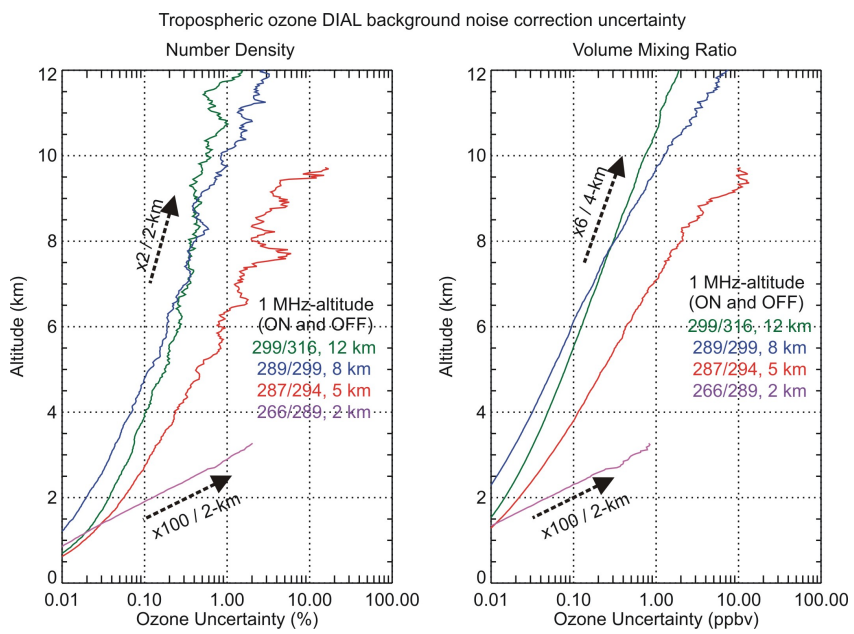

Figure 6. Same as Fig. 5, but for typical tropospheric ozone channels.

noise is no longer constant with altitude, and the background correction becomes much more uncertain. The uncertainty associated with nonlinear fits is typically larger than that associated with a linear fit, but most importantly, the actual altitude dependence of the signal-induced noise is usually unknown, and an additional uncertainty component that cannot be quantified accurately should be introduced. For this reason, it is strongly recommended to design lidar receivers in such a way that no signal-induced noise is present at all. 


\subsection{Uncertainty owing to the ozone absorption cross section differential}

Uncertainty owing to the ozone absorption cross section differential is computed by applying Eq. (4) to the DIAL equation (Eq. 24). The actual magnitude of this uncertainty can be very different depending on the type of backscatter (Rayleigh or Raman), and depending on the source of ozone absorption cross section used Eq. (26). Temperature-dependent ozone absorption cross sections values originate from various published works by spectroscopy groups around the world (e.g., Gorshelev et al., 2014; Serdyuchenko et al., 2014; Bass and Paur, 1984; Bogumil et al., 2003; Chehade et al., 2013; Daumont et al., 1992; Brion et al., 1998; Burrows et al., 1999). These groups usually provide at least one type of uncertainty estimate associated with the cross section values. Occasionally, they provide separate components owing to systematic and random effects. If present, these two components are not introduced and propagated similarly. To account for this distinction, the subscripts " $R$ " (for random) and " $S$ " (for systematic) will be used thereafter whenever needed. Expressions for the ozone uncertainty owing to the absorption cross section differential are now provided for four common cases.

\subsubsection{Random component}

In this case, the random component of the cross sections uncertainty $u_{\sigma \mathrm{O}_{3}}$ is used to derive the random component of the cross section differential uncertainty (no covariance terms).

Equation (4) is applied to the DIAL equation (Eq. 24) assuming no covariance terms from the cross section differential Eq. (26). For elastic (Rayleigh) backscatter DIAL systems, the corresponding component is propagated to ozone number density and mixing ratio using

$$
\begin{aligned}
& u_{\mathrm{NO}_{3}\left(\Delta \sigma \mathrm{O}_{3} R\right)}(k)= \\
& \frac{2 N_{\mathrm{O}_{3}}(k)}{\left|\Delta \sigma_{\mathrm{O}_{3}}(k)\right|} \sqrt{u_{\sigma \mathrm{O}_{3} 1(R)}^{2}(k)+u_{\sigma \mathrm{O}_{3} 3(R)}^{2}(k)} \\
& u_{q \mathrm{O}_{3}\left(\Delta \sigma \mathrm{O}_{3} R\right)}(k)= \\
& \frac{2 q_{\mathrm{O}_{3}}(k)}{\left|\Delta \sigma_{\mathrm{O}_{3}}(k)\right|} \sqrt{u_{\sigma \mathrm{O}_{3 \_} 1(R)}^{2}(k)+u_{\sigma \mathrm{O}_{3 \_} 3(R)}^{2}(k)} \text {. }
\end{aligned}
$$

For Raman backscatter DIAL systems, this uncertainty component is propagated to ozone number density and mixing ratio using

$$
\begin{aligned}
& u_{\mathrm{NO}_{3}\left(\Delta \sigma \mathrm{O}_{3} R\right)}(k)=\frac{N_{\mathrm{O}_{3}}(k)}{\left|\Delta \sigma_{\mathrm{O}_{3}}(k)\right|} \\
& \sqrt{u_{\sigma \mathrm{O}_{3} \_1(R)}^{2}(k)+u_{\sigma \mathrm{O}_{3} 2(R)}^{2}(k)+u_{\sigma \mathrm{O}_{3} 3(R)}^{2}(k)+u_{\sigma \mathrm{O}_{3} 4(R)}^{2}(k)} \\
& u_{q \mathrm{O}_{3}\left(\Delta \sigma \mathrm{O}_{3} R\right)}(k)=\frac{q_{\mathrm{O}_{3}}(k)}{\left|\Delta \sigma_{\mathrm{O}_{3}}(k)\right|} \\
& \sqrt{u_{\sigma \mathrm{O}_{3} \_1(R)}^{2}(k)+u_{\sigma \mathrm{O}_{3} \_(R)}^{2}(k)+u_{\sigma \mathrm{O}_{3} \_3(R)}^{2}(k)+u_{\sigma \mathrm{O}_{3} \_4(R)}^{2}(k)} \text {. }
\end{aligned}
$$

\subsubsection{Systematic component}

The cross sections' uncertainty component owing to systematic effects is not always present or reported. It is most often estimated by comparing several cross section datasets and observing biases between those datasets. The expression for the propagation of this component depends on the degree of correlation between the datasets used. Here we consider only two cases: when a unique source of cross section is used for all wavelengths (i.e., dataset originating from a single set of laboratory measurements), and when two independent cross section datasets are used for the ON and OFF wavelengths.

In the first case, it is assumed that the same dataset is used for the absorption cross sections at all wavelengths. The systematic component of the cross sections' uncertainty $u_{\sigma} \mathrm{O}_{3}(S)$ is used to derive a systematic component of the cross section differential's uncertainty $u_{\Delta_{\sigma} \mathrm{O}_{3}(S)}$ (Eq. 27) assuming full correlation between all wavelengths. In this case the same expression holds for both Rayleigh and Raman backscatter channels:

$$
\begin{aligned}
& u_{\mathrm{NO}_{3}\left(\Delta \sigma \mathrm{O}_{3} S\right)}(k)=\frac{N_{\mathrm{O}_{3}}(k)}{\left|\Delta \sigma_{\mathrm{O}_{3}}(k)\right|} \\
& \left|u_{\sigma \mathrm{O}_{3} \_1(S)}(k)+u_{\sigma \mathrm{O}_{3} \_2(S)}(k)-u_{\sigma \mathrm{O}_{3} \_3(S)}(k)-u_{\sigma \mathrm{O}_{3} \_4(S)}(k)\right| \\
& u_{q \mathrm{O}_{3}\left(\Delta \sigma \mathrm{O}_{3} S\right)}(k)=\frac{q_{\mathrm{O}_{3}}(k)}{\left|\Delta \sigma_{\mathrm{O}_{3}}(k)\right|} \\
& \left|u_{\sigma \mathrm{O}_{3} \_1(S)}(k)+u_{\sigma \mathrm{O}_{3} 2(S)}(k)-u_{\sigma \mathrm{O}_{3} \_3(S)}(k)-u_{\sigma \mathrm{O}_{3} \_4(S)}(k)\right| .
\end{aligned}
$$

In the second case, it is assumed that two independent datasets are used for the cross sections at the ON and OFF wavelengths. Though usually not the case, this situation can occur because laboratory studies often focus on specific spectral regions, not necessarily covering all the wavelengths in use by a particular DIAL system. With the assumption of two independent cross section datasets, the systematic component of the cross sections uncertainty reported by both datasets is assumed randomized (Type-B estimation). Therefore, the uncertainty component owing to systematic effects should be propagated, assuming that (1) the cross section values used within the same dataset are fully correlated, and (2) none of the cross section values of one dataset are correlated with a cross section value of the other dataset. The resulting ozone uncertainty component can then be written for both Rayleigh and Raman backscatter channels as follows:

$u_{\mathrm{NO}_{3}\left(\Delta \sigma \mathrm{O}_{3} S\right)}(k)=\frac{N_{\mathrm{O}_{3}}(k)}{\left|\Delta \sigma_{\mathrm{O}_{3}}(k)\right|}$

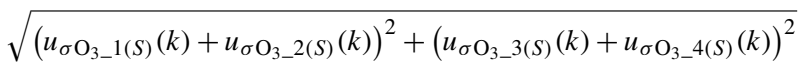

$u_{q \mathrm{O}_{3}\left(\Delta \sigma \mathrm{O}_{3} S\right)}(k)=\frac{q_{\mathrm{O}_{3}}(k)}{\left|\Delta \sigma_{\mathrm{O}_{3}}(k)\right|}$

$\sqrt{\left(u_{\sigma \mathrm{O}_{3} \_1(S)}(k)+u_{\sigma \mathrm{O}_{3} \_2(S)}(k)\right)^{2}+\left(u_{\sigma \mathrm{O}_{3} \_3(S)}(k)+u_{\sigma \mathrm{O}_{3} \_4(S)}(k)\right)^{2}}$. 
In Eqs. (51)-(54), the Rayleigh backscatter case simply consists of replacing subscripts " 3 " and " 4 " by " 1 " and " 2 " respectively.

Equations (47)-(54) show that the relative uncertainty in the retrieved ozone is directly proportional to the relative uncertainty in the ozone absorption cross section, which makes the latter the main source of uncertainty in the nominal region of the ozone DIAL method (Godin-Beekmann and Nair, 2012). Figure 7 shows, for several of the configurations just described and for several stratospheric and tropospheric ozone DIAL pairs, the ozone number density relative uncertainty as a function of the absorption cross section relative uncertainty. In all cases shown, it is assumed that all absorption cross sections have the same relative uncertainty. For stratospheric ozone DIAL pairs (308/355 and 332/387), the absorption cross section at the $\mathrm{ON}$ wavelength is much larger than that at the OFF wavelength, resulting in an ozone relative uncertainty mostly dominated by the absorption cross section uncertainty at the $\mathrm{ON}$ wavelength, and therefore leading to a one-to-one relationship (nearly diagonal straight line). For tropospheric ozone DIAL pairs (299/316, 289/299, $266 / 289$, and 287/294), the absorption cross sections at the ON and "OFF" wavelengths are closer to each other. As a result, the curves depart slightly from the diagonal observed for the stratospheric pairs. A 1-to-1 relationship (diagonal) is also observed for the all-systematic case as a result of the linear combination of Eqs. (51)-(52).

\subsection{Uncertainty owing to the Rayleigh extinction cross section differential}

An approach similar to that used for the ozone absorption cross section differential uncertainty can be used for the Rayleigh extinction cross section differential uncertainty by applying Eq. (4) to the DIAL equation (Eq. 25) and the cross section differential equation (Eq. 27). Analytical expressions of Rayleigh scattering based on atmospheric composition usually provide better cross section estimates than laboratory studies, e.g., Bates (1984); Eberhard (2010); Bucholtz (1995). Using an analytical expression to compute Rayleigh extinction cross sections is equivalent to considering the case of a single-source component (namely, the analytical function), therefore implying full correlation between all values. Under this assumption, the Rayleigh extinction cross section differential uncertainty propagated to ozone number density and mixing ratio can be written for Rayleigh and Raman backscatter channels:

$$
\begin{aligned}
& u_{\mathrm{NO}_{3}(\Delta \sigma M S)}(k)=N_{\mathrm{a}}(k) \\
& \left|\frac{u_{\sigma M_{-} 1(S)}(k)+u_{\sigma M_{-} 2(S)}(k)-u_{\sigma M_{-} 3(S)}(k)-u_{\sigma M_{-} 4(S)}(k)}{\Delta \sigma_{\mathrm{O}_{3}}(k)}\right| \\
& u_{q \mathrm{O}_{3}(\Delta \sigma M S)}(k)= \\
& \left|\frac{u_{\sigma M_{-} 1(S)}(k)+u_{\sigma M_{\_} 2(S)}(k)-u_{\sigma M_{-} 3(S)}(k)-u_{\sigma M_{-} 4(S)}(k)}{\Delta \sigma_{\mathrm{O}_{3}}(k)}\right| \text {. }
\end{aligned}
$$

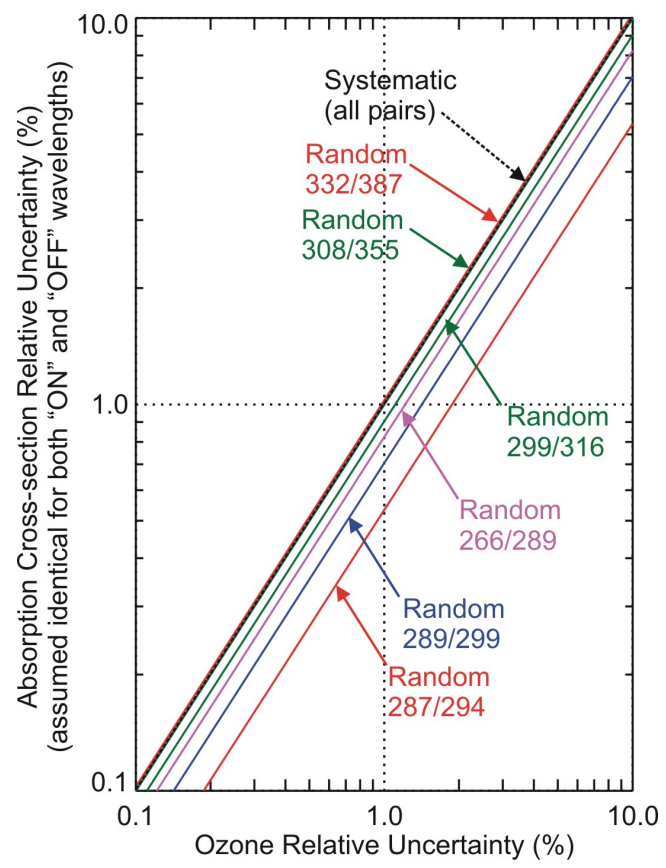

Figure 7. Ozone relative uncertainty $(\%)$ as a function of absorption cross section relative uncertainty (\%), assuming that all cross sections have the same relative uncertainty. Solid red, green, blue, and purple curves are used for cases of independent (random) datasets, and a dashed black curve is used for the case of full correlation between all cross sections (systematic).

When cross section uncertainties owing to only random effects are used and for Rayleigh backscatter channels, the Rayleigh extinction cross section differential uncertainty $u_{\mathrm{NO}_{3}\left(\triangle_{\sigma M R}\right)}$ propagated to ozone number density and mixing ratio can be written as follows:

$u_{\mathrm{NO}_{3}(\Delta \sigma M R)}(k)=\frac{2 N_{\mathrm{a}}(k)}{\left|\Delta \sigma_{\mathrm{O}_{3}}(k)\right|} \sqrt{u_{\sigma M_{-} 1(R)}^{2}(k)+u_{\sigma M_{-} 3(R)}^{2}(k)}$

$u_{q \mathrm{O}_{3}(\Delta \sigma M R)}(k)=\frac{2 \sqrt{u_{\sigma M_{-} 1(R)}^{2}(k)+u_{\sigma M_{-} 3(R)}^{2}(k)}}{\left|\Delta \sigma_{\mathrm{O}_{3}}(k)\right|}$.

For Raman backscatter channels, this uncertainty component can be written as follows:

$u_{\mathrm{NO}_{3}(\Delta \sigma M R)}(k)=\frac{N_{\mathrm{a}}(k)}{\left|\Delta \sigma_{\mathrm{O}_{3}}(k)\right|}$

$\sqrt{u_{\sigma M \_1(R)}^{2}(k)+u_{\sigma M \_2(R)}^{2}(k)+u_{\sigma M_{-} 3(R)}^{2}(k)+u_{\sigma M_{-} 4(R)}^{2}(k)}$

$u_{q \mathrm{O}_{3}(\Delta \sigma M R)}(k)=$

$\sqrt{u_{\sigma M_{-} 1(R)}^{2}(k)+u_{\sigma M_{-}(R)}^{2}(k)+u_{\sigma M_{-} 3(R)}^{2}(k)+u_{\sigma M_{-} 4(R)}^{2}(k)}$ $\left|\Delta \sigma_{\mathrm{O}_{3}}(k)\right|$

Equations (56), (58), and (60) show that for a specific DIAL pair, the lidar-retrieved mixing ratio uncertainty is directly 

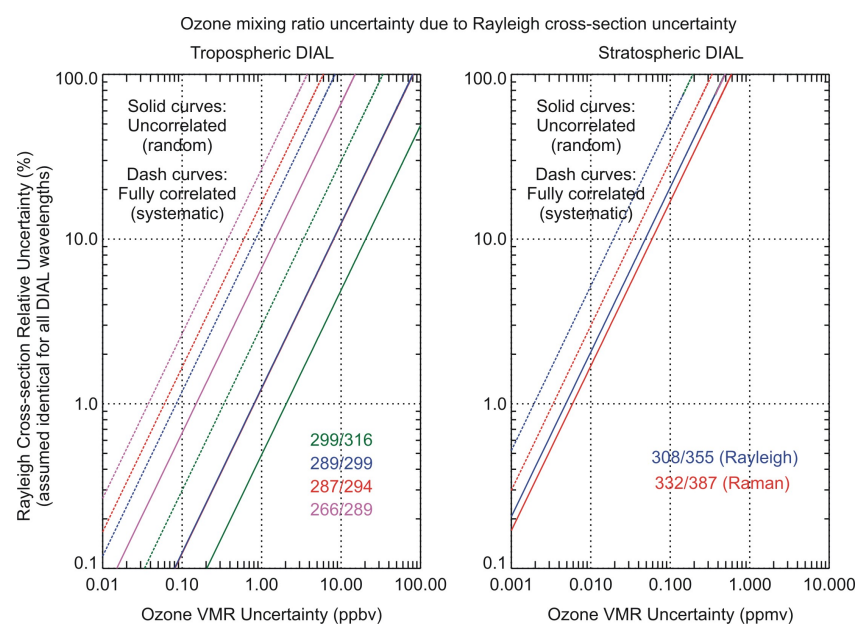

Figure 8. Ozone mixing ratio uncertainty as a function of Rayleigh cross section relative uncertainty (\%), assuming that all cross sections used have the same relative uncertainty. Solid curves are used for cases of independent (random) cross section datasets, and dashed curves are used for the case of full correlation between all cross sections.

proportional to the relative uncertainty in the Rayleigh cross section. Figure 8 shows, for several tropospheric (left plot) and stratospheric (right plot) ozone DIAL pairs, the ozone mixing ratio uncertainty as a function of the Rayleigh cross section relative uncertainty. In the figure, it is assumed that all Rayleigh cross sections have the same relative uncertainty value. A cross section relative uncertainty of $100 \%$ leads to an ozone number density uncertainty which has a magnitude that is equal to the error that results from neglecting the Rayleigh extinction correction. For a particular value of Rayleigh cross section relative uncertainty, the DIAL pairs with longer wavelengths (e.g., 299/316 for tropospheric systems, and the Raman pair for stratospheric systems) yield larger ozone mixing ratio uncertainties. Similar behavior was reported for the aerosol interference (Völger et al., 1996; Eisele and Trickl, 2005).

\subsection{Uncertainty owing to the interfering gases' cross section differential}

Once again, an approach similar to that used for the ozone absorption and Rayleigh cross section differentials can be used for the absorption cross section differential of the interfering gases. The resulting uncertainty components owing to random and systematic effects and propagated to ozone number density and mixing ratio can be written for $\mathrm{NO}_{2}$ and $\mathrm{SO}_{2}$ (ig $=\mathrm{NO}_{2}, \mathrm{SO}_{2}$ ). The particular case of absorption by $\mathrm{O}_{2}$ in the Herzberg and Wulf bands region is presented in the next paragraph.
For random effects and the Rayleigh backscatter case, we have the following:

$$
\begin{aligned}
& u_{\mathrm{NO}_{3}(\Delta \sigma \mathrm{ig} R)}(k)= \\
& \frac{2 N_{\mathrm{ig}}(k)}{\left|\Delta \sigma_{\mathrm{O}_{3}}(k)\right|} \sqrt{u_{\sigma \mathrm{ig} \_1(R)}^{2}(k)+u_{\sigma \mathrm{ig} \_3(R)}^{2}(k)} \\
& u_{q \mathrm{O}_{3}(\Delta \sigma \mathrm{ig} R)}(k)= \\
& \frac{2 q_{\mathrm{ig}}(k)}{\left|\Delta \sigma_{\mathrm{O}_{3}}(k)\right|} \sqrt{u_{\sigma \mathrm{ig} \_1(R)}^{2}(k)+u_{\sigma \mathrm{ig} \_3(R)}^{2}(k) .}
\end{aligned}
$$

For random effects and the Raman backscatter case, we have the following:

$u_{\mathrm{NO}_{3}(\Delta \sigma \operatorname{ig} R)}(k)=\frac{N_{\mathrm{ig}}(k)}{\left|\Delta \sigma_{\mathrm{O}_{3}}(k)\right|}$

$\sqrt{u_{\sigma \mathrm{ig} \_1(R)}^{2}(k)+u_{\sigma \mathrm{ig} \_2(R)}^{2}(k)+u_{\sigma \mathrm{ig} \_3(R)}^{2}(k)+u_{\sigma \mathrm{ig} \_4(R)}^{2}(k)}$

$u_{q \mathrm{O}_{3}(\Delta \sigma \mathrm{ig} R)}(k)=\frac{q_{\mathrm{ig}}(k)}{\left|\Delta \sigma_{\mathrm{O}_{3}}(k)\right|}$

$\sqrt{u_{\sigma \mathrm{ig} \_1(R)}^{2}(k)+u_{\sigma \mathrm{ig} \_2(R)}^{2}(k)+u_{\sigma \mathrm{ig} \_3(R)}^{2}(k)+u_{\sigma \mathrm{ig} \_4(R)}^{2}(k)}$.

For systematic effects, if using a single dataset for both ON and OFF wavelengths, for both Rayleigh and Raman backscatter, we have the following:

$$
\begin{aligned}
& u_{\mathrm{NO}_{3}(\Delta \sigma \mathrm{ig} S)}(k)=\frac{N_{\mathrm{ig}}(k)}{\left|\Delta \sigma_{\mathrm{O}_{3}}(k)\right|} \\
& \left|u_{\sigma \mathrm{ig} \_1(S)}(k)+u_{\sigma \mathrm{ig} \_2(S)}(k)-u_{\sigma \mathrm{ig} \_3(S)}(k)-u_{\sigma \mathrm{ig} \_4(S)}(k)\right| \\
& u_{q \mathrm{O}_{3}(\Delta \sigma \mathrm{ig} S)}(k)=\frac{q_{\mathrm{ig}}(k)}{\left|\Delta \sigma_{\mathrm{O}_{3}}(k)\right|} \\
& \left|u_{\sigma \mathrm{ig} \_1(S)}(k)+u_{\sigma \mathrm{ig} \_2(S)}(k)-u_{\sigma \mathrm{ig} \_3(S)}(k)-u_{\sigma \mathrm{ig} \_4(S)}(k)\right| .
\end{aligned}
$$

For systematic effects, if using two different datasets for ON and OFF wavelengths, for both Rayleigh and Raman backscatter, we have the following:

$$
\begin{aligned}
& u_{\mathrm{NO}_{3}(\Delta \sigma \mathrm{ig} S)}(k)=\frac{N_{\mathrm{ig}}(k)}{\left|\Delta \sigma_{\mathrm{O}_{3}}(k)\right|} \\
& \sqrt{\left(u_{\sigma \mathrm{ig} \_1(S)}(k)+u_{\sigma \mathrm{ig} \_2(S)}(k)\right)^{2}+\left(u_{\sigma \mathrm{ig} \_3(S)}(k)+u_{\sigma \mathrm{ig} \_4(S)}(k)\right)^{2}} \\
& u_{q \mathrm{O}_{3}(\Delta \sigma \operatorname{ig} S)}(k)=\frac{q_{\mathrm{ig}}(k)}{\left|\Delta \sigma_{\mathrm{O}_{3}}(k)\right|} \\
& \sqrt{\left(u_{\sigma \mathrm{ig} \_1(S)}(k)+u_{\sigma \mathrm{ig} \_2(S)}(k)\right)^{2}+\left(u_{\sigma \mathrm{ig} \_3(S)}(k)+u_{\sigma \mathrm{ig} \_4(S)}(k)\right)^{2}} .
\end{aligned}
$$

This time the ozone mixing ratio uncertainty is proportional to the relative uncertainty in the cross section and to the mixing ratio of the interfering gas. Figure 9 shows, for several tropospheric (left plot) and stratospheric (right plot) ozone DIAL pairs, the expected ozone mixing ratio uncertainty per part-per-billion of $\mathrm{NO}_{2}$, and as a function of the $\mathrm{NO}_{2}$ cross section relative uncertainty. In the figure, it is assumed that all $\mathrm{NO}_{2}$ cross sections have the same relative uncertainty. A 


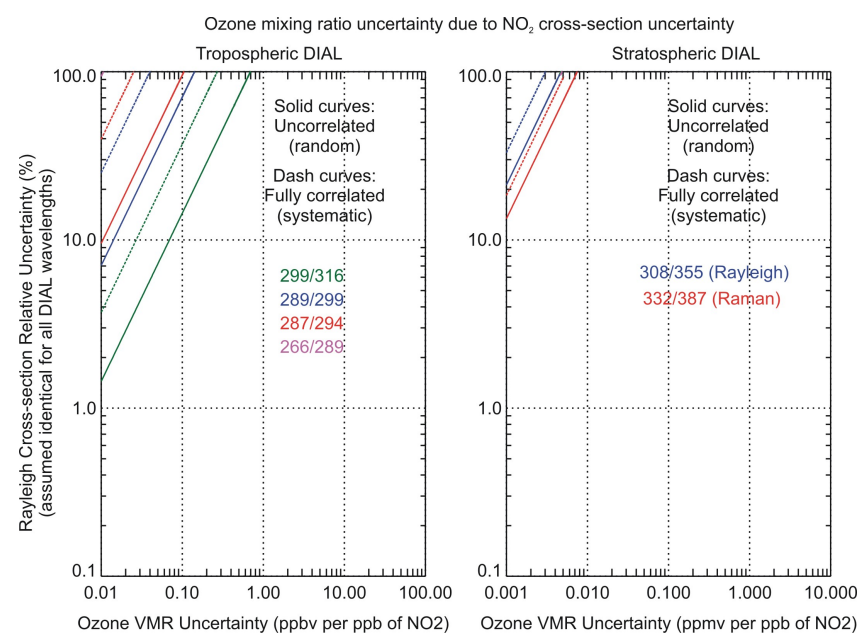

Figure 9. Ozone mixing ratio uncertainty as a function of $\mathrm{NO}_{2}$ cross section relative uncertainty (\%), assuming that all cross sections used have the same relative uncertainty. Solid curves are used for cases of independent (random) cross section datasets, and dashed curves are used for the case of full correlation between all cross sections.
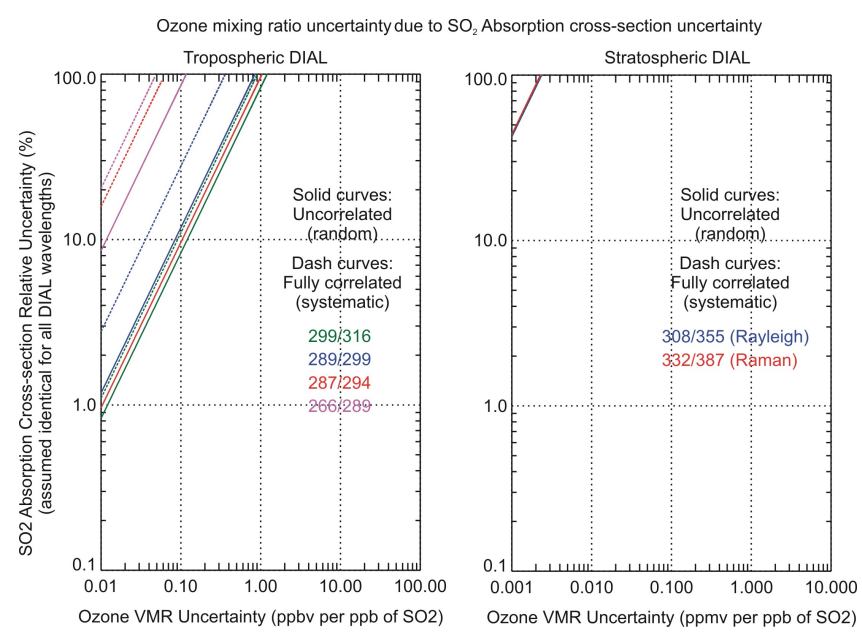

Figure 10. Ozone mixing ratio uncertainty as a function of $\mathrm{SO}_{2}$ cross section relative uncertainty (\%), assuming that all cross sections used have the same relative uncertainty. Solid curves are used for cases of independent (random) cross section datasets, and dashed curves are used for the case of full correlation between all cross sections.

cross section relative uncertainty of $100 \%$ is equivalent to neglecting $\mathrm{NO}_{2}$ absorption. DIAL pairs with longer wavelengths yield a larger ozone mixing ratio uncertainty due to the large $\mathrm{NO}_{2}$ cross section values in the UV region. In "normal" $\mathrm{NO}_{2}$ background conditions, the relative impact of $\mathrm{NO}_{2}$ absorption on retrieved ozone remains very small for both tropospheric and stratospheric ozone systems.

Figure 10 is similar to Fig. 9, but for $\mathrm{SO}_{2}$. The ozone mixing ratio uncertainty owing to $\mathrm{SO}_{2}$ cross section uncertainty is almost negligible for stratospheric DIAL pairs (Higgins band) because of the weak $\mathrm{SO}_{2}$ absorption in this region compared to that of ozone. The impact of $\mathrm{SO}_{2}$ absorption on retrieved ozone is therefore negligible except in the case of heavy $\mathrm{SO}_{2}$ loads (i.e., 100 ppbv or above).

\subsection{Uncertainty owing to $\mathrm{O}_{2}$ absorption cross section differential}

An approach similar to that used for the other cross section differentials can be used for the $\mathrm{O}_{2}$ absorption in the region of the Herzberg and Wulf bands (Fally et al., 2000). This interfering absorption only impacts DIAL measurements using wavelengths shorter than $294 \mathrm{~nm}$. In addition, the impact depends on the position of the laser line with respect to the position of the individual Herzberg lines. When the lines are coincident and the resulting absorption non-negligible, the expression of uncertainty for this component owing to random and systematic effects and propagated to ozone number density and mixing ratio can be formulated in the same manner as the other interfering gases, with the exception that the $\mathrm{O}_{2}$ mixing ratio $q_{\mathrm{O}_{2}}$ is assumed as a well-known constant $\left(q_{\mathrm{O}_{2}} \sim 0.209\right)$.

For random effects and the Rayleigh backscatter case, we have the following:

$$
\begin{aligned}
& u_{\mathrm{NO}_{3}\left(\Delta \sigma \mathrm{O}_{2} R\right)}(k)= \\
& \frac{2 q_{\mathrm{O}_{2}} N_{\mathrm{a}}(k)}{\left|\Delta \sigma_{\mathrm{O}_{3}}(k)\right|} \sqrt{u_{\sigma \mathrm{O}_{2} \_1(R)}^{2}(k)+u_{\sigma \mathrm{O}_{2} 3(R)}^{2}(k)} \\
& u_{q \mathrm{O}_{3}\left(\Delta \sigma \mathrm{O}_{2} R\right)}(k)= \\
& \frac{2 q_{\mathrm{O}_{2}}}{\mid \Delta \sigma_{\mathrm{O}_{3}(k) \mid}} \sqrt{u_{\sigma \mathrm{O}_{2} \_1(R)}^{2}(k)+u_{\sigma \mathrm{O}_{2 \_} 3(R)}^{2}(k) .}
\end{aligned}
$$

For random effects and the Raman backscatter case, we have the following:

$$
\begin{aligned}
& u_{\mathrm{NO}_{3}\left(\Delta \sigma \mathrm{O}_{2} R\right)}(k)=\frac{q_{\mathrm{O}_{2}} N_{\mathrm{a}}(k)}{\left|\Delta \sigma_{\mathrm{O}_{3}}(k)\right|} \\
& \sqrt{u_{\sigma \mathrm{O}_{2} \_1(R)}^{2}(k)+u_{\sigma \mathrm{O}_{2 \_} 2(R)}^{2}(k)+u_{\sigma \mathrm{O}_{2} 3(R)}^{2}(k)+u_{\sigma \mathrm{O}_{2} \_4(R)}^{2}(k)} \\
& u_{q \mathrm{O}_{3}\left(\Delta \sigma \mathrm{O}_{2} R\right)}(k)=\frac{q_{\mathrm{O}_{2}}}{\left|\Delta \sigma_{\mathrm{O}_{3}}(k)\right|} \\
& \sqrt{u_{\sigma \mathrm{O}_{2} \_1(R)}^{2}(k)+u_{\sigma \mathrm{O}_{2} \_2(R)}^{2}(k)+u_{\sigma \mathrm{O}_{2} 33(R)}^{2}(k)+u_{\sigma \mathrm{O}_{2} \_4(R)}^{2}(k)} .
\end{aligned}
$$

For systematic effects, if using a single dataset, for both Rayleigh and Raman backscatter, we have the following:

$$
\begin{aligned}
& u_{\mathrm{NO}_{3}\left(\Delta \sigma \mathrm{O}_{2} S\right)}(k)=\frac{q_{\mathrm{O}_{2}} N_{\mathrm{a}}(k)}{\left|\Delta \sigma_{\mathrm{O}_{3}}(k)\right|} \\
& \left|u_{\sigma \mathrm{O}_{2} \_1(S)}(k)+u_{\sigma \mathrm{O}_{2} \_2(S)}(k)-u_{\sigma \mathrm{O}_{2} \_3(S)}(k)-u_{\sigma \mathrm{O}_{2} \_4(S)}(k)\right| \\
& u_{q \mathrm{O}_{3}\left(\Delta \sigma \mathrm{O}_{2} S\right)}(k)=\frac{q_{\mathrm{O}_{2}}}{\left|\Delta \sigma_{\mathrm{O}_{3}}(k)\right|} \\
& \left|u_{\sigma \mathrm{O}_{2} \_1(S)}(k)+u_{\sigma \mathrm{O}_{2} \_2(S)}(k)-u_{\sigma \mathrm{O}_{2} \_3(S)}(k)-u_{\sigma \mathrm{O}_{2} \_4(S)}(k)\right| .
\end{aligned}
$$

For systematic effects, if using two different datasets for ON and OFF wavelengths, for both Rayleigh and Raman 


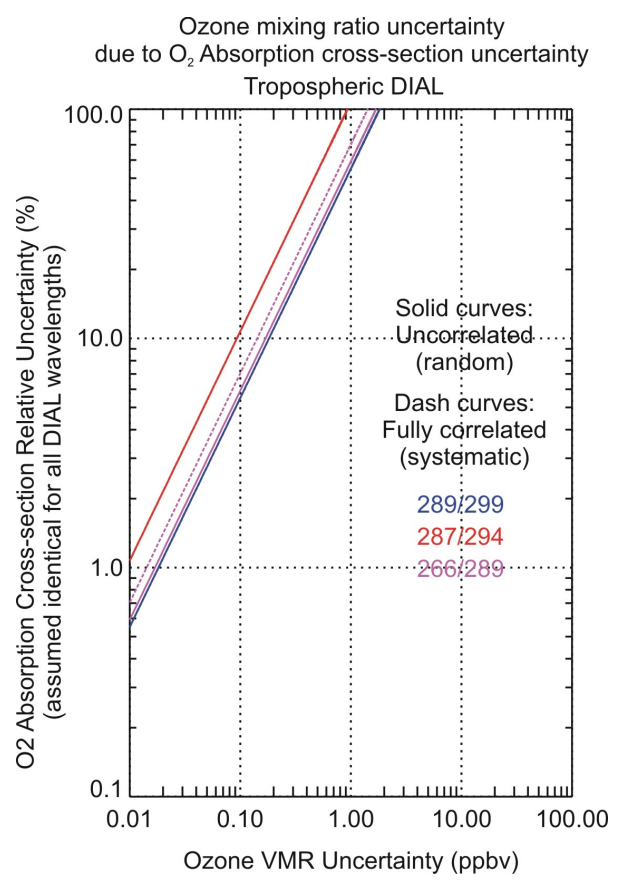

Figure 11. Ozone mixing ratio uncertainty as a function of $\mathrm{O}_{2}$ cross section relative uncertainty (\%), assuming that all cross sections used have the same relative uncertainty. Solid curves are used for cases of independent (random) cross section datasets, and dashed curves are used for the case of full correlation between all cross sections.

backscatter, we have the following:

$u_{\mathrm{NO}_{3}\left(\Delta \sigma \mathrm{O}_{2} S\right)}(k)=\frac{q \mathrm{O}_{2} N_{\mathrm{a}}(k)}{\left|\Delta \sigma_{\mathrm{O}_{3}}(k)\right|}$

$\sqrt{\left(u_{\sigma \mathrm{O}_{2} \_1(S)}(k)+u_{\sigma \mathrm{O}_{2} \_2(S)}(k)\right)^{2}+\left(u_{\sigma \mathrm{O}_{2} \_3(S)}(k)+u_{\sigma \mathrm{O}_{2} \_4(S)}(k)\right)^{2}}$

$u_{q \mathrm{O}_{3}\left(\Delta \sigma \mathrm{O}_{2} S\right)}(k)=\frac{q_{\mathrm{O}_{2}}}{\left|\Delta \sigma_{\mathrm{O}_{3}}(k)\right|}$

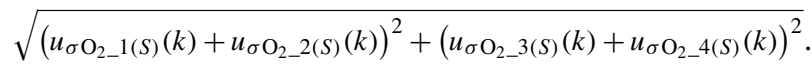

Equations (69)-(76) show that the ozone mixing ratio uncertainty owing to $\mathrm{O}_{2}$ absorption is directly proportional to the relative uncertainty in the $\mathrm{O}_{2}$ cross section. Figure 11 shows, for several tropospheric ozone DIAL pairs, the expected ozone mixing ratio uncertainty as a function of the $\mathrm{O}_{2}$ cross section relative uncertainty. In the figure, it is assumed that all $\mathrm{O}_{2}$ cross sections have the same relative uncertainty value. A cross section relative uncertainty of $100 \%$ is equivalent to neglecting $\mathrm{O}_{2}$ absorption. As already mentioned, the discrete Herzberg absorption lines are very narrow and the effective cross sections depend strongly on the position of the laser line with respect to those lines. Therefore Fig. 11 is shown as an example, only knowing that the effective cross sections may differ greatly from one tropospheric ozone lidar instrument to another.

\subsection{Uncertainty owing to interfering gases' atmospheric profiles}

Another source of uncertainty introduced in Eq. (25) is the a priori use of ancillary $\mathrm{NO}_{2}$ and $\mathrm{SO}_{2}$ number density or mixing ratio profiles. The term "a priori" here does not mean that the ozone DIAL retrieval uses a variational/optimal estimation method (it does not), but simply means that the information comes from ancillary (i.e., non-lidar) measurements or models, and is input as "truth" in the ozone DIAL processing chain. The input quantities in this case can be of different nature, namely mixing ratio or number density (e.g., Ahmad et al., 2007; Bauer et al., 2012; Bracher et al., 2005; Brohede et al., 2007; Brühl et al., 2013; Cao et al., 2006; Höpfner et al., 2013; He et al., 2014; McLinden et al., 2014). In order to ensure self-consistency in our measurement model, input quantities independent of air number density should be chosen.

1. When the input quantity independent of air number density is the interfering gas' number density $N_{\text {ig }}$ (with uncertainty $u_{N \mathrm{ig}}$ ), the propagated ozone number density and mixing ratio uncertainties should be written as follows:

$u_{\mathrm{NO}_{3}(N \mathrm{ig})}(k)=\left|\frac{\Delta \sigma_{\mathrm{ig}}(k)}{\Delta \sigma_{\mathrm{O}_{3}}(k)}\right| u_{N \mathrm{ig}}(k)$

with $i g=\mathrm{NO}_{2}, \mathrm{SO}_{2}$

$u_{q \mathrm{O}_{3}(N \mathrm{ig})}(k)=\frac{1}{N_{\mathrm{a}}(k)}\left|\frac{\Delta \sigma_{\mathrm{ig}}(k)}{\Delta \sigma_{\mathrm{O}_{3}}(k)}\right| u_{N \mathrm{ig}}(k)$

with $\mathrm{ig}=\mathrm{NO}_{2}, \mathrm{SO}_{2}$.

2. When the input quantity independent of air number density is the mixing ratio of the interfering gas $q_{\text {ig }}$ (with uncertainty $u_{q \mathrm{ig}}$ ), the propagated ozone number density and mixing ratio uncertainties should be written as follows:

$$
\begin{aligned}
& u_{\mathrm{NO}_{3}(q \mathrm{ig})}(k)=N_{\mathrm{a}}(k)\left|\frac{\Delta \sigma_{N \mathrm{ig}}(k)}{\Delta \sigma_{\mathrm{O}_{3}}(k)}\right| u_{q \mathrm{ig}}(k) \\
& \text { with } i g=\mathrm{NO}_{2}, \mathrm{SO}_{2} \\
& u_{q \mathrm{O}_{3}(q \mathrm{ig})}(k)=\left|\frac{\Delta \sigma_{N \mathrm{ig}}(k)}{\Delta \sigma_{\mathrm{O}_{3}}(k)}\right| u_{q \mathrm{ig}}(k) \\
& \text { with } i g=\mathrm{NO}_{2}, \mathrm{SO}_{2} .
\end{aligned}
$$

Equation (80) shows that the lidar-retrieved ozone mixing ratio uncertainty owing to the interfering gases is directly proportional to the gases' mixing ratio uncertainty. Figure 12 shows, for several tropospheric (left) and stratospheric (right) ozone DIAL pairs, the ozone mixing ratio uncertainty as a function of the $\mathrm{NO}_{2}$ mixing ratio uncertainty. This uncertainty component remains very small in most cases. One exception is for highly polluted boundary layer conditions where $\mathrm{NO}_{2}$ mixing ratio can reach 10 to $100 \mathrm{ppbv}$, resulting in ozone mixing ratio uncertainty of 0.5 to $5 \mathrm{ppbv}$ for 


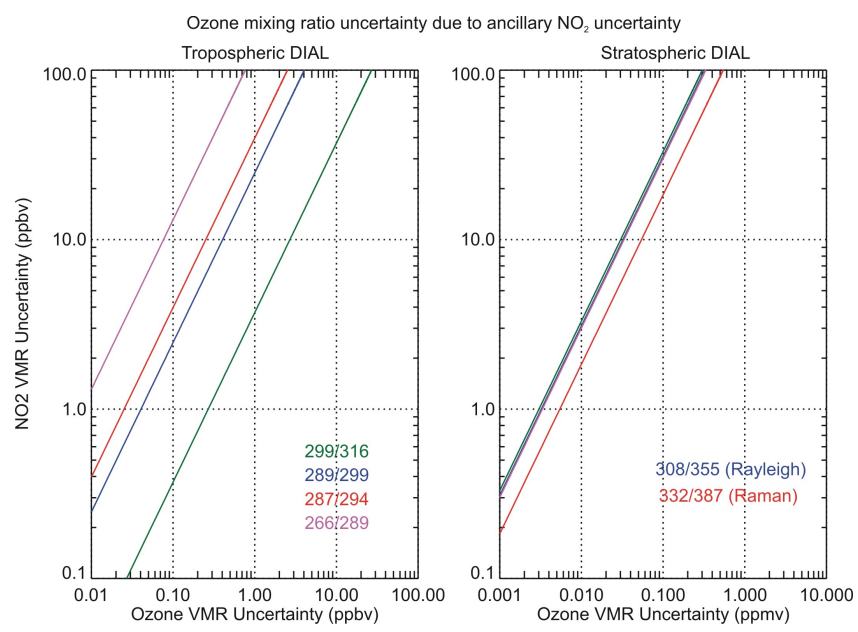

Figure 12. Ozone mixing ratio uncertainty as a function of $\mathrm{NO}_{2}$ mixing ratio uncertainty (ppbv). Left plot: tropospheric ozone DIAL pairs (uncertainty in ppbv). Right plot: stratospheric ozone DIAL pairs (uncertainty in ppmv).

the most commonly used DIAL wavelengths. Figure 13 is similar to Fig. 12, but for interfering gas $\mathrm{SO}_{2}$. Tropospheric ozone DIAL pairs are more affected in this case due to the larger $\mathrm{SO}_{2}$ absorption cross section differential.

\subsection{Uncertainty owing to air number density, temperature and pressure profiles}

The last input quantity to consider in our ozone DIAL measurement model is ancillary air number density. The air density is generally not estimated directly, but rather derived from air temperature and pressure. Here we provide expressions for the propagation of this uncertainty component for both cases, i.e., when air number density is considered the input quantity, and when temperature and pressure are considered the input quantities.

\subsubsection{Estimation from air number density profile}

If the air number density $N_{\mathrm{a}}$ is not derived from air temperature and pressure, then its uncertainty $u_{N_{\mathrm{a}}}$ can be propagated directly to ozone number density and mixing ratio uncertainty by applying Eq. (4) to Eqs. (25) and (26) respectively. The result, however, will be different whether mixing ratio or number density is used as input quantity for the interfering gases' profiles.

1. If number density is used as input quantity for the interfering gases' profiles,

$$
\begin{aligned}
& u_{\mathrm{NO}_{3}\left(N_{\mathrm{a}}\right)}(k)=\left|\frac{\Delta \sigma_{\mathrm{M}}+q_{\mathrm{O}_{2}} \Delta \sigma_{\mathrm{O}_{2}}(k)}{\Delta \sigma_{\mathrm{O}_{3}}(k)}\right| u_{N_{\mathrm{a}}}(k) \\
& u_{q \mathrm{O}_{3}\left(N_{\mathrm{a}}\right)}(k)=\left|q_{\mathrm{O}_{3}}+\frac{\Delta \sigma_{\mathrm{M}}+q_{\mathrm{O}_{2}} \Delta \sigma_{\mathrm{O}_{2}}(k)}{\Delta \sigma_{\mathrm{O}_{3}}(k)}\right| \frac{u_{N_{\mathrm{a}}}(k)}{N_{\mathrm{a}}(k)} .
\end{aligned}
$$

2. If mixing ratio is used as input quantity for the interfering gases' profiles,

$$
\begin{aligned}
& u_{\mathrm{NO}_{3}\left(N_{\mathrm{a}}\right)}(k)= \\
& \left|\frac{\Delta \sigma_{\mathrm{M}}+\Delta \sigma_{\mathrm{NO}_{2}}(k) q_{\mathrm{NO}_{2}}(k)+\Delta \sigma_{\mathrm{SO}_{2}}(k) q_{\mathrm{SO}_{2}}(k)+q_{\mathrm{O}_{2}} \Delta \sigma_{\mathrm{O}_{2}}(k)}{\Delta \sigma_{\mathrm{O}_{3}}(k)}\right| \\
& u_{N_{\mathrm{a}}}(k) \\
& u_{q \mathrm{O}_{3}\left(N_{\mathrm{a}}\right)}(k)= \\
& \left|q_{\mathrm{O}_{3}}+\frac{\Delta \sigma_{\mathrm{M}}+\Delta \sigma_{\mathrm{NO}_{2}}(k) q_{\mathrm{NO}_{2}}(k)+\Delta \sigma_{\mathrm{SO}_{2}}(k) q_{\mathrm{SO}_{2}}(k)+q_{\mathrm{O}_{2}} \Delta \sigma_{\mathrm{O}_{2}}(k)}{\Delta \sigma_{\mathrm{O}_{3}}(k)}\right| \\
& \quad \frac{u_{N_{\mathrm{a}}}(k)}{N_{\mathrm{a}}(k)} .
\end{aligned}
$$

In Eqs. (81)-(84), the effect of absorption by $\mathrm{O}_{2}$ in the Herzberg and Wulf bands region is included. This term can be neglected if the ON and OFF wavelengths are longer than $294 \mathrm{~nm}$. In Eq. (84), it is again assumed that the interfering gases' mixing ratio profiles are independent of the air number density profile (no covariance terms involved).

\subsubsection{Estimation from air temperature and pressure profile}

When using radiosonde measurements or meteorological analysis, the air number density is typically derived from air temperature $T_{\mathrm{a}}$ and pressure $p_{\mathrm{a}}$ following the ideal gas law (with $k_{\mathrm{B}}$ being the Boltzmann constant):

$N_{\mathrm{a}}(k)=\frac{p_{\mathrm{a}}(k)}{k_{\mathrm{B}} T_{\mathrm{a}}(k)}$.

In this case, air number density is no longer the input quantity, but air temperature and pressure are. The propagation of uncertainty due to the use of an a priori temperature and pressure profile now depends on the degree of correlation between pressure and temperature.

1. If temperature and pressure are measured or computed independently, with uncertainty estimates $u_{T_{\mathrm{a}}}$ and $u_{\mathrm{pa}}$ respectively, and if number density is used as input quantity for the interfering gases, the air number density uncertainty propagated to ozone number density and mixing ratio will be

$$
\begin{aligned}
& u_{\mathrm{NO}_{3}\left(N_{\mathrm{a}}\right)}(k)= \\
& \left|\frac{\Delta \sigma_{\mathrm{M}}+q_{\mathrm{O}_{2}} \Delta \sigma_{\mathrm{O}_{2}}(k)}{\Delta \sigma_{\mathrm{O}_{3}}(k)}\right| N_{\mathrm{a}}(k) \sqrt{\frac{u_{\mathrm{pa}}^{2}(k)}{p_{\mathrm{a}}^{2}(k)}+\frac{u_{T_{\mathrm{a}}}^{2}(k)}{T_{\mathrm{a}}^{2}(k)}} \\
& u_{q \mathrm{O}_{3}\left(N_{\mathrm{a}}\right)}(k)= \\
& \left|\frac{\Delta \sigma_{\mathrm{M}}+q_{\mathrm{O}_{2}} \Delta \sigma_{\mathrm{O}_{2}}(k)}{\Delta \sigma_{\mathrm{O}_{3}}(k)}\right| \sqrt{\frac{u_{\mathrm{pa}}^{2}(k)}{p_{\mathrm{a}}^{2}(k)}+\frac{u_{T_{\mathrm{a}}}^{2}(k)}{T_{\mathrm{a}}^{2}(k)}} .
\end{aligned}
$$

2. If temperature and pressure are measured or computed independently, with uncertainty estimates $u_{T_{\mathrm{a}}}$ and $u_{\mathrm{pa}}$ 
respectively, and if mixing ratio is used as input quantity for the interfering gases, the air number density uncertainty propagated to ozone number density will be

$u_{\mathrm{NO}_{3}\left(N_{\mathrm{a}}\right)}(k)=$

$\left|\frac{\Delta \sigma_{\mathrm{M}}+q_{\mathrm{NO}_{2}} \Delta \sigma_{\mathrm{NO}_{2}}(k)+q_{\mathrm{SO}_{2}} \Delta \sigma_{\mathrm{SO}_{2}}(k)+q_{\mathrm{O}_{2}} \Delta \sigma_{\mathrm{O}_{2}}(k)}{\Delta \sigma_{\mathrm{O}_{3}}(k)}\right|$

$N_{\mathrm{a}}(k) \sqrt{\frac{u_{\mathrm{pa}}^{2}(k)}{p_{\mathrm{a}}^{2}(k)}+\frac{u_{T_{\mathrm{a}}}^{2}(k)}{T_{\mathrm{a}}^{2}(k)}}$.

3. If temperature and pressure are known to be fully correlated, and if number density is used as input quantity for the interfering gases, the ozone number density uncertainty owing to air number density will be written as follows:

$$
\begin{aligned}
& u_{\mathrm{NO}_{3}\left(N_{\mathrm{a}}\right)}(k)= \\
& \left|\frac{\Delta \sigma_{\mathrm{M}}+q_{\mathrm{O}_{2}} \Delta \sigma_{\mathrm{O}_{2}}(k)}{\Delta \sigma_{\mathrm{O}_{3}}(k)}\right| N_{\mathrm{a}}(k)\left|\frac{u_{\mathrm{pa}}(k)}{p_{\mathrm{a}}(k)}-\frac{u_{T_{\mathrm{a}}}(k)}{T_{\mathrm{a}}(k)}\right| .
\end{aligned}
$$

4. If temperature and pressure are known to be fully correlated, and if mixing ratio is used as input quantity for the interfering gases, the ozone number density uncertainty owing to air number density will be written as follows:

$$
\begin{aligned}
& u_{\mathrm{NO}_{3}\left(N_{\mathrm{a}}\right)}(k)= \\
& \left|\frac{\Delta \sigma_{\mathrm{M}}+q_{\mathrm{NO}_{2}} \Delta \sigma_{\mathrm{NO}_{2}}(k)+q_{\mathrm{SO}_{2}} \Delta \sigma_{\mathrm{SO}_{2}}(k)+q_{\mathrm{O}_{2}} \Delta \sigma_{\mathrm{O}_{2}}(k)}{\Delta \sigma_{\mathrm{O}_{3}}(k)}\right| \\
& N_{\mathrm{a}}(k)\left|\frac{u_{\mathrm{pa}}(k)}{p_{\mathrm{a}}(k)}-\frac{u_{T_{\mathrm{a}}}(k)}{T_{\mathrm{a}}(k)}\right| .
\end{aligned}
$$

Because the ozone and interfering gases' absorption cross sections depend on temperature (and pressure), the covariance terms of the cross section differentials and the air number density covariance matrix are not strictly zero. However, the correlation coefficients are expected to be very small and the assumption of two independent input quantities still holds.

Figure 14 shows the stratospheric ozone relative uncertainty (left) and mixing ratio uncertainty (right) as a function of the ancillary air number density, temperature or pressure uncertainty for typical midlatitude spring conditions. The solid curves represent the ozone uncertainty for each percent of air number density uncertainty, the dashed curves represent the ozone uncertainty for each degree of air temperature uncertainty, and the dotted curves represent the ozone uncertainty for each $0.1 \mathrm{hPa}$ of air pressure uncertainty. The largest ozone uncertainty in the upper stratosphere is that owing to pressure. Figure 15 is similar to Fig. 14, but for tropospheric ozone DIAL systems. DIAL pairs using longer wavelengths (e.g., 299/316 nm) are more impacted than pairs using shorter wavelengths. Noteworthy, with current pressure-temperature

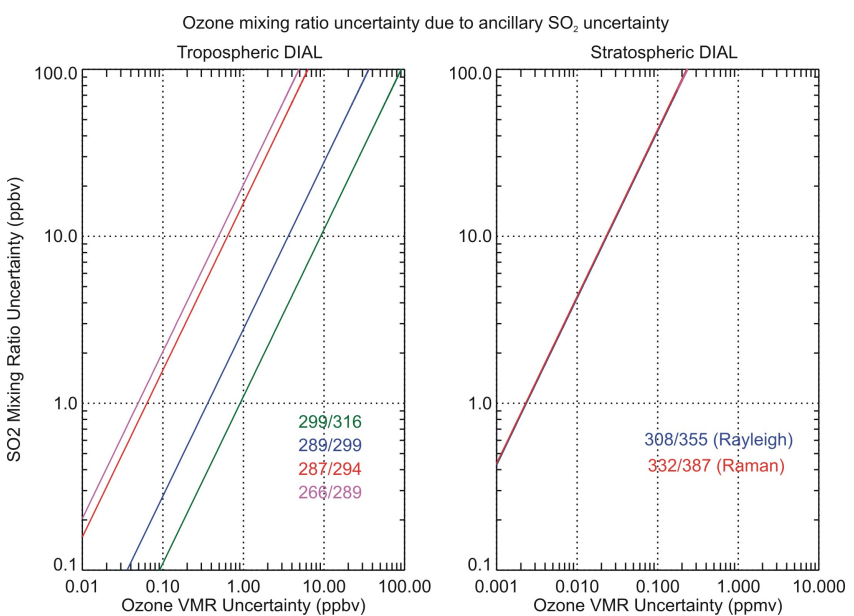

Figure 13. Same as Fig. 12, but for interfering gas $\mathrm{SO}_{2}$.

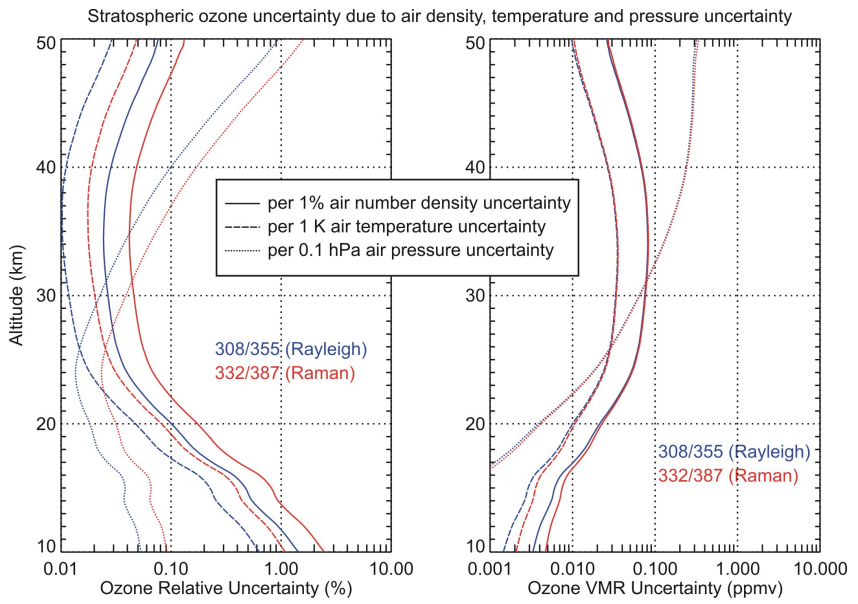

Figure 14. Stratospheric ozone relative uncertainty (left) and mixing ratio uncertainty (right) as a function of air number density, temperature, and pressure uncertainty, for typical midlatitude spring conditions. The solid curves represent the ozone uncertainty per percent of air number density uncertainty, the dashed curves represent the ozone uncertainty per degree of air temperature uncertainty, and the dotted curves represent the ozone uncertainty per $0.1 \mathrm{hPa}$ of air pressure uncertainty.

measurement capabilities (typically $0.5 \mathrm{~K}$ and $0.1 \mathrm{hPa}$ uncertainties), the lidar-retrieved ozone uncertainty owing to temperature is about 10 times larger than that owing to pressure uncertainty.

\subsection{Propagation of uncertainty when combining two intensity ranges}

Ozone DIAL instruments are most often designed with multiple signal intensity ranges in order to maximize the overall altitude range of the profile. Reduced signal intensity is achieved using neutral density filters or other optical systems attenuating the Rayleigh-backscattered signals, or using 


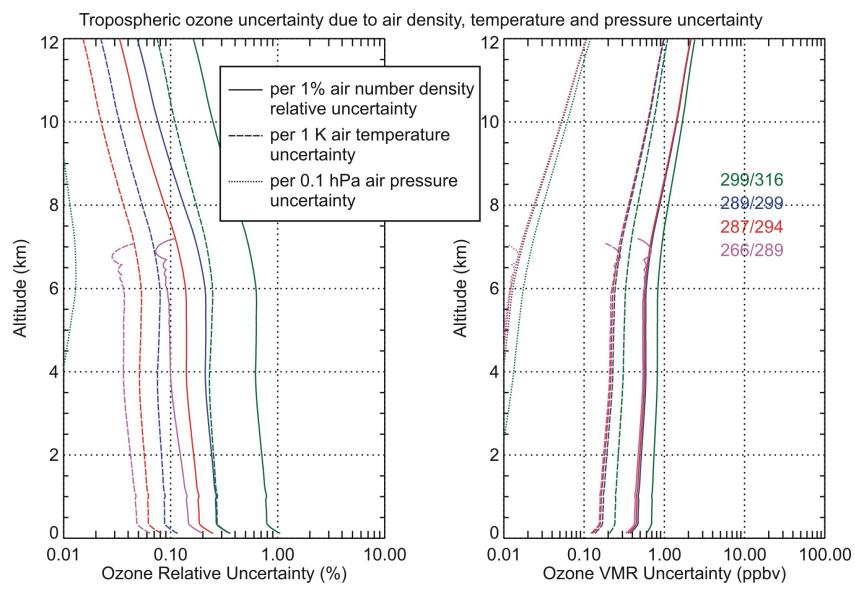

Figure 15. Same as Fig. 14, but for tropospheric ozone DIAL systems.

Raman backscatter channels, which typically are 750 times weaker than Rayleigh backscatter channels. Until now, our ozone DIAL measurement model referred to a single intensity range. We now provide an example of formulation for the propagation of uncertainty when the number densities for two intensity ranges are combined to produce a single profile. Combining individual intensity ranges into a single profile can occur either during lidar signal processing or after the ozone number density is calculated individually for each intensity range. Here we present the case of combining ozone number density after it was calculated for individual intensity ranges. The case of combining the lidar signals is presented in our companion paper (Leblanc et al., 2016b). The principles governing the propagation of uncertainty are the same in both cases.

A single profile covering the entire useful range of the instrument is typically obtained by combining the most accurate overlapping sections of the profiles retrieved from individual ranges. The thickness of the transition region typically varies from a few meters to a few kilometers, depending on the instrument and on the intensity ranges considered. Assuming that the transition region's bottom altitude is $z\left(k_{1}\right)$ and its top altitude is $z\left(k_{2}\right)$, the combined ozone profile between a low range $i_{\mathrm{L}}$ and a high range $i_{\mathrm{H}}$, is typically obtained by computing a weighted average of the ozone values retrieved for each range:

$$
\begin{aligned}
& N_{\mathrm{O}_{3}}(k)=w(k) N_{\mathrm{O}_{3}}\left(k, i_{\mathrm{L}}\right) \\
& +(1-w(k)) N_{\mathrm{O}_{3}}\left(k, i_{\mathrm{H}}\right) k_{1}<k<k_{2} \text { and } 0<w(k)<1 \\
& q_{\mathrm{O}_{3}}(k)=w(k) q_{\mathrm{O}_{3}}\left(k, i_{\mathrm{L}}\right) \\
& +(1-w(k)) q_{\mathrm{O}_{3}}\left(k, i_{\mathrm{H}}\right) k_{1}<k<k_{2} \text { and } 0<w(k)<1 .
\end{aligned}
$$

Using this formulation, all uncertainty components associated with atmospheric extinction corrections are propagated without change as they do not depend on the intensity range considered:

$u_{\mathrm{NO}_{3}(X)}(k)=u_{\mathrm{NO}_{3}(X)}\left(k, i_{\mathrm{L}}\right)=u_{\mathrm{NO}_{3}(X)}\left(k, i_{\mathrm{H}}\right)$ for all $k$
$u_{q \mathrm{O}_{3}(X)}(k)=u_{q \mathrm{O}_{3}(X)}\left(k, i_{\mathrm{L}}\right)=u_{q \mathrm{O}_{3}(X)}\left(k, i_{\mathrm{H}}\right)$ for all $k$,

with $X=\Delta \sigma \mathrm{O}_{3}, \Delta \sigma M, \quad N_{\mathrm{a}}, \Delta \sigma \mathrm{ig}, \quad \mathrm{Nig}, \Delta \sigma \mathrm{O}_{2}$ and $\mathrm{ig}=\mathrm{NO}_{2}, \mathrm{SO}_{2}$.

Because of its random nature, ozone uncertainty owing to detection noise for the combined profile is obtained by adding in quadrature (no covariance terms) the detection noise uncertainties of the individual ranges:

$u_{\mathrm{NO}_{3}(\mathrm{DET})}(k)=$

$\sqrt{\left(w(k) u_{\mathrm{NO}_{3}(\mathrm{DET})}\left(k, i_{\mathrm{L}}\right)\right)^{2}+\left((1-w(k)) u_{\mathrm{NO}_{3}(\mathrm{DET})}\left(k, i_{\mathrm{H}}\right)\right)^{2}}$

$k_{1}<k<k_{2}$

$u_{q} \mathrm{O}_{3}(\mathrm{DET})(k)=$

$\sqrt{\left(w(k) u_{q \mathrm{O}_{3}(\mathrm{DET})}\left(k, i_{\mathrm{L}}\right)\right)^{2}+\left((1-w(k)) u_{q \mathrm{O}_{3}(\mathrm{DET})}\left(k, i_{\mathrm{H}}\right)\right)^{2}}$

$k_{1}<k<k_{2}$.

Assuming that the saturation correction and the background noise extraction have been applied consistently for all intensity ranges within the same data processing algorithm, the associated uncertainty components can be propagated to the combined profile assuming full correlation between the intensity ranges:

$$
\begin{aligned}
& u_{\mathrm{NO}_{3}(X)}(k)= \\
& \left|w(k) u_{\mathrm{NO}_{3}(X)}\left(k, i_{\mathrm{L}}\right)+(1-w(k)) u_{\mathrm{NO}_{3}(X)}\left(k, i_{\mathrm{H}}\right)\right| k_{1}<k<k_{2} \\
& u_{q \mathrm{O}_{3}(X)}(k)= \\
& \left|w(k) u_{q \mathrm{O}_{3}(X)}\left(k, i_{\mathrm{L}}\right)+(1-w(k)) u_{q \mathrm{O}_{3}(X)}\left(k, i_{\mathrm{H}}\right)\right| k_{1}<k<k_{2},
\end{aligned}
$$

with $X=$ SAT, BKG.

\subsection{Ozone combined standard uncertainty}

Having reviewed and propagated all the independent uncertainty components considered in our ozone DIAL measurement model, we can combine them into a single total uncertainty estimate.

If number density is used as input quantity for the interfering gases, the combined standard uncertainty of retrieved ozone number density and mixing ratio can be written as fol- 
lows:

$$
\begin{aligned}
& u_{\mathrm{NO}_{3}}(k)= \\
& u_{\mathrm{NO}_{3}(\mathrm{DET})}^{2}(k)+u_{\mathrm{NO}_{3}(\mathrm{SAT})}^{2}(k)+u_{\mathrm{NO}_{3}(\mathrm{BKG})}^{2}(k) \\
& +u_{\mathrm{NO}_{3}\left(N_{\mathrm{a}}\right)}^{2}(k)+u_{\mathrm{NO}_{3}\left(\mathrm{NNO}_{2}\right)}^{2}(k)+u_{\mathrm{NO}_{3}\left(\mathrm{NSO}_{2}\right)}^{2}(k) \\
& +u_{\mathrm{NO}_{3}\left(\Delta \sigma \mathrm{O}_{3} R\right)}^{2}(k)+u_{\mathrm{NO}_{3}\left(\Delta \sigma \mathrm{NO}_{2} R\right)}^{2}(k) \\
& +u_{\mathrm{NO}_{3}\left(\Delta \sigma \mathrm{SO}_{2} R\right)}^{2}(k)+u_{\mathrm{NO}_{3}\left(\Delta \sigma \mathrm{O}_{2} R\right)}^{2}(k) \\
& +u_{\mathrm{NO}_{3}\left(\Delta \sigma \mathrm{O}_{3} S\right)}^{2}(k)+u_{\mathrm{NO}_{3}\left(\Delta \sigma \mathrm{NO}_{2} S\right)}^{2}(k) \\
& +u_{\mathrm{NO}_{3}\left(\Delta \sigma \mathrm{SO}_{2} S\right)}^{2}(k)+u_{\mathrm{NO}_{3}\left(\Delta \sigma \mathrm{O}_{2} S\right)}^{2}(k) \\
& +u_{\mathrm{NO}_{3}(\Delta \sigma M)}^{2}(k) \\
& u_{q \mathrm{O}_{3}}(k)= \\
& \begin{array}{l}
u_{q \mathrm{O}_{3}(\mathrm{DET})}^{2}(k)+u_{q \mathrm{O}_{3}(\mathrm{SAT})}^{2}(k)+u_{q \mathrm{O}_{3}(\mathrm{BKG})}^{2}(k) \\
+u_{q \mathrm{O}_{3}\left(N_{\mathrm{a}}\right)}^{2}(k)+u_{q \mathrm{O}_{3}\left(N_{\left.\mathrm{NO}_{2}\right)}(k)+u_{q \mathrm{O}_{3}\left(N \mathrm{SO}_{2}\right)}^{2}(k)\right.}^{2}(k)+u_{q \mathrm{O}_{3}\left(\Delta \sigma \mathrm{NO}_{2} R\right)}^{2}(k) \\
+u_{q \mathrm{O}_{3}\left(\Delta \sigma \mathrm{O}_{3} R\right)}^{2}(k)+u_{q \mathrm{O}_{3}\left(\Delta \sigma \mathrm{O}_{2} R\right)}(k) \\
+u_{q \mathrm{O}_{3}\left(\Delta \sigma \mathrm{SO}_{2} R\right)}^{2}(k)+u_{q \mathrm{O}_{3}\left(\Delta \sigma \mathrm{NO}_{2} S\right)}(k) \\
+u_{q \mathrm{O}_{3}\left(\Delta \sigma \mathrm{O}_{3} S\right)}^{2}(k)+(k)+u_{q \mathrm{O}_{3}\left(\Delta \sigma \mathrm{O}_{2} S\right)}^{2}(k) \\
+u_{q \mathrm{O}_{3}\left(\Delta \sigma \mathrm{SO}_{2} S\right)}^{2}(k) \\
\left.+u_{q \mathrm{O}_{3}(\Delta \sigma M)}^{2}\right)
\end{array}
\end{aligned}
$$

If mixing ratio is used as input quantity for the interfering gases, the combined standard uncertainty of retrieved ozone number density and mixing ratio can be written as follows:

$$
\begin{aligned}
& u_{\mathrm{NO}_{3}}(k)=
\end{aligned}
$$

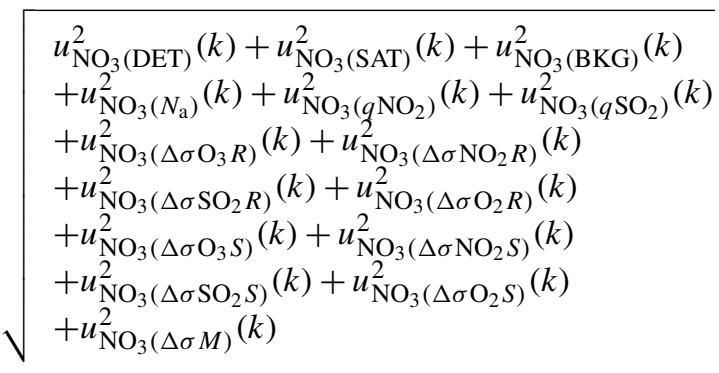

$$
\begin{aligned}
& u_{q \mathrm{O}_{3}}(k)= \\
& \begin{array}{l}
u_{q \mathrm{O}_{3}(\mathrm{DET})}^{2}(k)+u_{q \mathrm{O}_{3}(\mathrm{SAT})}^{2}(k)+u_{q \mathrm{O}_{3}(\mathrm{BKG})}^{2}(k) \\
+u_{q \mathrm{O}_{3}\left(N_{\mathrm{a}}\right)}^{2}(k)+u_{q \mathrm{O}_{3}\left(q \mathrm{NO}_{2}\right)}^{2}(k)+u_{q \mathrm{O}_{3}\left(q \mathrm{SO}_{2}\right)}^{2}(k) \\
+u_{q \mathrm{O}_{3}\left(\Delta \sigma \mathrm{O}_{3} R\right)}^{2}(k)+u_{q \mathrm{O}_{3}\left(\Delta \sigma \mathrm{NO}_{2} R\right)}^{2}(k) \\
+u_{q \mathrm{O}_{3}\left(\Delta \sigma \mathrm{SO}_{2} R\right)}^{2}(k)+u_{q \mathrm{O}_{3}\left(\Delta \sigma \mathrm{O}_{2} R\right)}^{2}(k) \\
+u_{q \mathrm{O}_{3}\left(\Delta \sigma \mathrm{O}_{3} S\right)}^{2}(k)+u_{q \mathrm{O}_{3}\left(\Delta \sigma \mathrm{NO}_{2} S\right)}^{2}(k) \\
+u_{q \mathrm{O}_{3}\left(\Delta \sigma \mathrm{SO}_{2} S\right)}^{2}(k)+u_{q \mathrm{O}_{3}\left(\Delta \sigma \mathrm{O}_{2} S\right)}^{2}(k) \\
+u_{q \mathrm{O}_{3}(\Delta \sigma M)}^{2}(k) .
\end{array}
\end{aligned}
$$

Though Eqs. (99)-(100) and Eqs. (101)-(102) are computed independently, the resulting combined uncertainty is quantitatively identical in both formulations if we assume identical input quantity uncertainty values. The only difference between the two sets of equations is a redistribution of the contribution of the components owing to the ancillary number densities or mixing ratios. Because of the correlated terms, the ozone combined standard uncertainty should not be computed for individual intensity ranges and then merged into a single profile. Instead, the individual uncertainty components should first be propagated to the merged profile (Eqs. 91-98) and then added in quadrature to obtain the combined standard uncertainty (Eqs. 99-102).

Similarly, the total combined ozone density (or mixing ratio) uncertainty can be used to characterize a single profile, but should not be used for the combination of "dependent" profiles (for example a climatology computed from multiple profiles measured by the same instrument). Instead, uncertainty components owing to systematic effects in altitude and/or time must be separated from components owing to random effects. Typically, uncertainty owing to detection noise will always be added in quadrature, while for other components, knowledge (type A or type B estimation) of the covariance matrix in the time and/or altitude dimension(s) will be needed. For this reason, it is recommended that a trace of each individual component is always kept together with the combined standard uncertainty.

\section{Two examples of actual ozone DIAL uncertainty budget}

The uncertainty components discussed in the previous section were quantitatively reviewed, for most cases, in parametric form, so that the order of magnitude of each component could be estimated for a wide range of instrument performance. Here we provide two actual examples using existing measurements from the Jet Propulsion Laboratory (JPL) tropospheric ozone DIAL at the NDACC site of Table Mountain Facility (California), and the JPL stratospheric ozone DIAL at the NDACC site of Mauna Loa Observatory (Hawai'i). In these two examples, the input quantities' uncertainty estimates are taken from the JPL in-house data processing software used to process the routine JPL lidar data archived at NDACC. A list of those input quantities and their uncertainty is compiled in Table 3.

\subsection{Ozone uncertainty budget for the JPL lidar at Mauna Loa Observatory, HI}

Figure 16 shows the full ozone uncertainty budget for a $2 \mathrm{~h}$ measurement obtained on 13 March 2009 from the JPL stratospheric ozone DIAL located at Mauna Loa Observatory, Hawai'i. The ozone number density uncertainty budget is on the left (in \%), the ozone mixing ratio uncertainty budget is on the right (in ppmv). All components previously identified are present except the three components associated with absorption by $\mathrm{SO}_{2}$ and $\mathrm{O}_{2}$, which are negligible. The results are presented for a typical variable vertical filtering scheme that accommodates the signal magnitude of the different DIAL pairs. The Mauna Loa ozone lidar com- 
Table 3. Input quantities and their uncertainty used to compute the ozone uncertainty budget presented in Figs. 16 and 17.

\begin{tabular}{|c|c|c|c|c|c|c|}
\hline $\begin{array}{l}\text { Input } \\
\text { quantity }\end{array}$ & $\begin{array}{l}\text { Dataset } \\
\text { name }\end{array}$ & $\begin{array}{l}\text { Domain of } \\
\text { validity }\end{array}$ & $\begin{array}{l}\text { Uncertainty } \\
\text { estimate } \\
\text { (random) }\end{array}$ & Reference & $\begin{array}{l}\text { Uncert. } \\
\text { name }\end{array}$ & $\begin{array}{l}\text { Uncert. } \\
\text { used here }\end{array}$ \\
\hline$\sigma_{\mathrm{O}_{3}}$ & DMB & $\begin{array}{l}195-345 \mathrm{~nm} \\
310-350 \mathrm{~nm} \\
350-830 \mathrm{~nm}\end{array}$ & $\begin{array}{l}1-1.5 \% \\
1.3-3.5 \% \\
5 \%\end{array}$ & $\begin{array}{l}\text { Malicet et al. (1995) } \\
\text { Daumont et al. (1992) } \\
\text { Brion et al. (1998) }\end{array}$ & $u_{\sigma_{\mathrm{O}_{3}}}$ & $\begin{array}{l}2 \% \\
4 \% \\
5 \%\end{array}$ \\
\hline$\sigma_{\mathrm{M}}$ & Eberhard & l & $2 \%$ & Eberhard (2010) & $u_{\sigma M}$ & $2 \%$ \\
\hline$T_{\mathrm{a}}$ & $\begin{array}{l}\text { MSISE-90 } \\
\text { NCEP- } \\
\text { NDSC } \\
\text { Radiosonde }\end{array}$ & $\begin{array}{l}>47 \mathrm{~km} \\
30-47 \mathrm{~km} \\
<30 \mathrm{~km}\end{array}$ & $\begin{array}{l}20 \mathrm{~K} \\
1-5 \mathrm{~K} \\
0.2-0.5 \mathrm{~K}\end{array}$ & $\begin{array}{l}\text { Hedin (1991) } \\
\text { Finger et al. (1993) } \\
\text { Hurst et al. (2011) }\end{array}$ & $u_{T_{\mathrm{a}}}$ & $\begin{array}{l}20 \mathrm{~K} \\
5 \mathrm{~K} \\
0.5 \mathrm{~K}\end{array}$ \\
\hline$p_{\mathrm{a}}$ & $\begin{array}{l}\text { MSISE-90 } \\
\text { NCEP- } \\
\text { NDSC } \\
\text { Radiosonde }\end{array}$ & $\begin{array}{l}>47 \mathrm{~km} \\
30-47 \mathrm{~km} \\
18-30 \mathrm{~km} \\
<18 \mathrm{~km}\end{array}$ & $\begin{array}{l}5 \% \\
5 \% \\
0.3 \mathrm{hPa} \\
0.5 \mathrm{hPa}\end{array}$ & $\begin{array}{l}\text { Hedin (1991) } \\
\text { Finger et al. (1993) } \\
\text { Hurst et al. (2011) } \\
\text { Hurst et al. (2011) }\end{array}$ & $u_{\mathrm{pa}}$ & $\begin{array}{l}5 \% \\
5 \% \\
0.3 \mathrm{hPa} \\
0.5 \mathrm{hPa}\end{array}$ \\
\hline$\sigma_{\mathrm{NO}_{2}}$ & Bogumil & $200-800 \mathrm{~nm}$ & $3.5 \%$ & Bogumil et al. (2003) & $u_{\sigma} \mathrm{NO}_{2}$ & $5 \%$ \\
\hline $\begin{array}{l}q \mathrm{NO}_{2} \\
\sigma_{\mathrm{SO}_{2}}\end{array}$ & $\begin{array}{l}\text { WACCM } \\
\text { Bogumil }\end{array}$ & $\begin{array}{l}0-50 \mathrm{~km} \\
200-800 \mathrm{~nm}\end{array}$ & $\begin{array}{l}10 \% \\
3-10 \%\end{array}$ & $\begin{array}{l}\text { Garcia et al. (2007) } \\
\text { Bogumil et al. (2003) }\end{array}$ & $\begin{array}{l}u_{q \mathrm{NO}_{2}} \\
u_{\sigma \mathrm{NO}_{2}}\end{array}$ & $\begin{array}{l}10 \% \\
5 \%\end{array}$ \\
\hline$q_{\mathrm{SO}_{2}}$ & $\begin{array}{l}\text { MIPAS } \\
\text { OMI }\end{array}$ & $\begin{array}{l}15-45 \mathrm{~km} \\
<15 \mathrm{~km}\end{array}$ & $\begin{array}{l}10 \% \\
30 \%\end{array}$ & $\begin{array}{l}\text { Hopfner et al. (2013) } \\
\text { McLinden et al. (2014) }\end{array}$ & $u_{q \mathrm{NO}_{2}}$ & $\begin{array}{l}10 \% \\
30 \%\end{array}$ \\
\hline$\sigma_{\mathrm{O}_{2}}$ & IASB & $120-294 \mathrm{~nm}$ & $10 \%$ & Fally et al. (2000) & $u_{\sigma_{\mathrm{O}_{2}}}$ & $10 \%$ \\
\hline
\end{tabular}

prises 3 DIAL pairs (Rayleigh high-intensity, Rayleigh lowintensity, and Raman), and the figures show the uncertainty profiles after all pairs have been combined into one single profile. The altitudes of transition from one pair to another are easily identifiable by looking at the magnitude of the uncertainty owing to saturation correction or to detection noise (light green and red curves respectively). Uncertainty owing to detection noise drops a first time between 18 and $20 \mathrm{~km}$ and then again between 30 and $32 \mathrm{~km}$, and at the same time, saturation correction uncertainty increases suddenly between 30 and $32 \mathrm{~km}$.

After optimal combination of all three DIAL pairs, the ozone number density standard uncertainty results mainly from three components, namely, Rayleigh extinction cross section differential (dark blue curve) at the bottom of the profile, ozone absorption cross section differential (dark green curve) in the middle of the profile, and detection noise (red curve) at the top of the profile. For the derived ozone mixing ratio (right plot), the uncertainty component associated with the a priori use of ancillary air pressure (light blue curve) becomes abruptly important above $30 \mathrm{~km}$ as a result of the transition between the a priori use of radiosonde measurement $(z<30 \mathrm{~km})$ and the a priori use of the NCEP analysis $(z>30 \mathrm{~km})$. The numerical change of pressure uncertainty at $30 \mathrm{~km}$ is reported in Table 3 . Like for ozone number density, the dominant source of ozone mixing ratio uncertainty above $45 \mathrm{~km}$ is detection noise.

\subsection{Ozone uncertainty budget for the tropospheric $\mathrm{O}_{3}$ DIAL at Table Mountain}

Figure 17 shows the full ozone uncertainty budget for a $2 \mathrm{~h}$ measurement obtained on 18 November 2009 by the tropospheric ozone DIAL located at JPL Table Mountain Facility (TMF), California. Once again, the ozone number density uncertainty budget is on the left (in \%), the ozone mixing ratio uncertainty budget is on the right (in ppmv). The TMF lidar samples air mostly above the boundary layer so the components associated with absorption by $\mathrm{SO}_{2}$ are negligible. In 2009, the TMF tropospheric ozone lidar comprised three DIAL pairs (Rayleigh high-intensity, Rayleigh mediumintensity, and Rayleigh low-intensity). Like in Fig. 16, the figures show the uncertainty profiles after all DIAL pairs were combined into a single profile. The altitudes of transition from one pair to another are 10 and $16 \mathrm{~km}$. The combined ozone number density standard uncertainty results mainly from the ozone absorption cross section differential uncertainty (dark green curve). Below $12 \mathrm{~km}$, the uncertainty owing to Rayleigh extinction cross section differential (dark blue curve), and owing to detection noise (red curve) are the other important components. Uncertainty owing to detection noise dominates in the upper part of the profile (above $22 \mathrm{~km})$. 

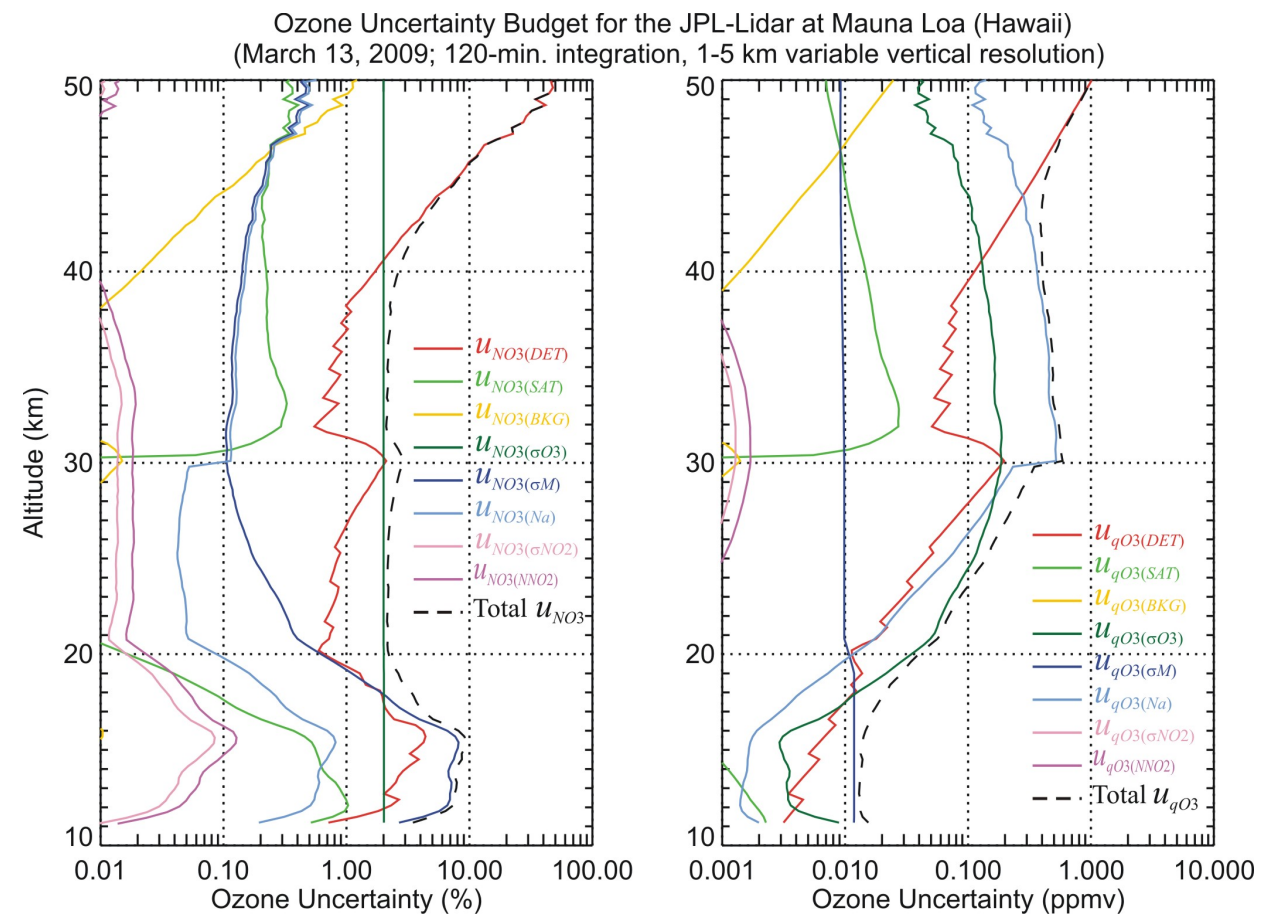

Figure 16. Example of ozone relative uncertainty (left) and mixing ratio uncertainty (right) budget computed for the JPL stratospheric ozone DIAL located at Mauna Loa Observatory (Hawai'i) using the standardized approach presented in this work (nighttime measurements).
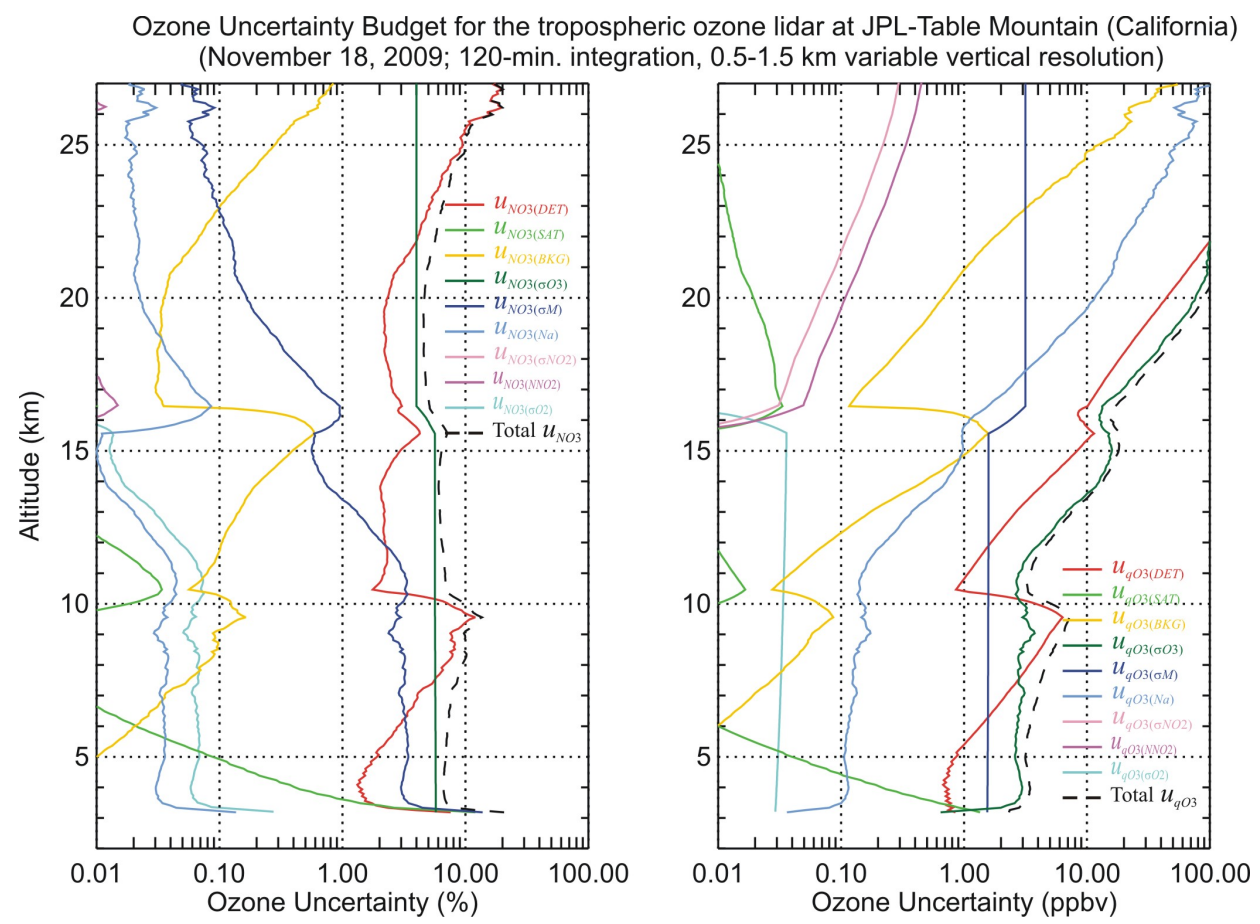

Figure 17. Same as Fig. 16, but for the tropospheric ozone DIAL system located at the JPL Table Mountain Facility (California) (nighttime measurements). 


\section{Conclusion}

The present article is the second of three companion papers on the recommendations made to the NDACC lidar community for the standardization of vertical resolution and uncertainty in their lidar data processing algorithms. Here the focus was on the ozone DIAL uncertainty budget. The definition of uncertainty recommended to be used for all NDACC lidar measurements is combined standard uncertainty, as defined by the BIPM (JCGM 200, 2012; JCGM 100, 2008). In the approach proposed here all the individual, independent uncertainty components are propagated in parallel through the data processing chain. It is only after the final signal transformation is applied (i.e., leading to the actual values of ozone number density and mixing ratio) that the individual uncertainty components are combined together to form the combined standard uncertainty, the primary and mandatory variable of the newly proposed NDACC-standardized ozone DIAL uncertainty budget.

The individual uncertainty components identified by the ISSI team comprise the random noise associated with signal detection, uncertainty due to saturation correction, background noise extraction, the absorption cross sections of $\mathrm{O}_{3}$, $\mathrm{NO}_{2}, \mathrm{SO}_{2}$, and $\mathrm{O}_{2}$ (if applicable), the molecular extinction cross sections, and the number densities of the air, $\mathrm{NO}_{2}$, and $\mathrm{SO}_{2}$ (if applicable). All these sources of uncertainty except detection noise imply correlated terms in the vertical dimension, which means that covariance terms must be taken into account when the lidar signal is vertically filtered. In addition, if the same detection hardware is shared by the $\mathrm{ON}$ and OFF channels, the covariance terms must be taken into account when the ON and OFF channels are combined. When computing the ozone cross section differentials and the interfering gases' cross section differentials, the covariance terms should also be taken into account if the same cross section dataset is used for the ON and OFF wavelengths.

The introduction and step-by-step propagation of each single uncertainty component through the ozone data processing chain was thoroughly reviewed by the ISSI team and detailed here. The validity of the approach and correctness of the recommended expressions were quantitatively verified using simulated lidar signals and Monte Carlo experiments. The details of these experiments are given in the ISSI team report (Leblanc et al., 2016a). The objective was not to estimate the magnitude of each uncertainty contribution, but to verify that the propagation expressions provided in Sect. 4 were theoretically correct and properly implemented.

Every source of uncertainty should be reported in the NDACC-archived metadata file. Providing quantitative information on the ancillary datasets used is also highly recommended. Whether or not using the NDACC-standardized uncertainty budget approach, the best estimate of the ozone combined standard uncertainty must be reported in the NDACC-archived data files. In addition, individual standard uncertainty components that contribute to the ozone com- bined uncertainty should be reported in the NDACC-archived data files whenever possible.

Typically, NDACC ozone lidar profiles are given as a function of altitude and for an averaging time period ranging between a few minutes and several hours. For each reported uncertainty component, the systematic or random nature of the underlying effects associated with this component should be reported in both altitude and time dimensions. When using multiple NDACC-archived ozone or temperature lidar profiles, for example, to produce a climatology, each reported uncertainty component must first be computed separately based on the expected systematic or random behavior of the process associated with it, and only after that, be combined.

Because each lidar instrument is unique, not all sources of uncertainty have been identified or reviewed in this paper. For unidentified sources, as well as uncertainty owing to analog detection, overlap correction, and particulate backscatter and extinction corrections mentioned earlier but not treated, the NDACC lidar investigators should use the same generic approach as that used for the sources identified and treated here, and should add those components to the uncertainty budget following the same definitions, methodologies, and propagation principles. It is advised that dedicated working groups be formed in the near future to address the standardization of the treatment of these uncertainty components.

The recommendations and approaches proposed by the ISSI team for ozone and temperature in the present paper and the other two companion papers can be largely extended to water vapor and aerosol.

\section{Data availability}

The data used to produce the figures shown here are not publicly available. However, they can be obtained by contacting the first author at thierry.leblanc@jpl.nasa.gov.

Acknowledgements. This work was initiated in response to the 2010 call for international teams of experts in Earth and Space Science by the International Space Science Institute (ISSI) in Bern, Switzerland. It could not have been performed without the travel and logistical support of ISSI. Part of the work described in this paper was carried out at the Jet Propulsion Laboratory, California Institute of Technology, under agreements with the National Aeronautics and Space Administration. Part of this work was carried out in support of the European Space Agency VALID project. Robert J. Sica would like to acknowledge the support of the Canadian National Sciences and Engineering Research Council for support of the University of Western Ontario lidar work.

Edited by: H. Maring

Reviewed by: two anonymous referees 


\section{References}

Ahmad, Z., McClain, C. R., Herman, J. R., Franz, B. A., Kwiatkowska, E. J., Robinson, W. D., Bucsela, E. J., and Tzortziou, M.: Atmospheric correction for $\mathrm{NO}_{2}$ absorption in retrieving water-leaving reflectances from the SeaWiFS and MODIS measurements, Appl. Opt., 46, 6504-6512, 2007.

Bass, A. M. and Paur, R. J.: The Ultraviolet Cross-sections of Ozone: I. The Measurements, Proc. Quadriennial Ozone Symp., Halkidiki, Greece, 606-616, 1984

Bates, D. R.: Rayleigh-scattering by air, Planet Space Sci., 32, 785790, doi:10.1016/0032-0633(84)90102-8, 1984.

Bauer, R., Rozanov, A., McLinden, C. A., Gordley, L. L., Lotz, W., Russell III, J. M., Walker, K. A., Zawodny, J. M., LadstätterWeißenmayer, A., Bovensmann, H., and Burrows, J. P.: Validation of SCIAMACHY limb $\mathrm{NO}_{2}$ profiles using solar occultation measurements, Atmos. Meas. Tech., 5, 1059-1084, doi:10.5194/amt-5-1059-2012, 2012.

Bogumil, K., Orphal, J., Homann, T., Voigt, S., Spietz, P., Fleischmann, O. C., Vogel, A., Hartmann, M., Kromminga, H., Bovensmann, H., Frerick, J., and Burrows, J. P.: Measurements of molecular absorption spectra with the SCIAMACHY preflight model: instrument characterization and reference data for atmospheric remote-sensing in the $230-2380 \mathrm{~nm}$ region, J. Photochem. Photobiol. A, 157, 167-184, doi:10.1016/s10106030(03)00062-5, 2003.

Bösenberg, J.: Instrument Development for Atmospheric Research and Monitoring, 1 ed., Transport and Chemical Transformation of Pollutants in the Troposphere, 8, edited by: Bösenberg, J., Brassington, D. J., and Simon, P. C., Springer-Verlag, Berlin Heidelberg, XIX, 396 pp., 1997.

Bracher, A., Sinnhuber, M., Rozanov, A., and Burrows, J. P.: Using a photochemical model for the validation of $\mathrm{NO}_{2}$ satellite measurements at different solar zenith angles, Atmos. Chem. Phys., 5, 393-408, doi:10.5194/acp-5-393-2005, 2005.

Brion, J., Chakir, A., Charbonnier, J., Daumont, D., Parisse, C., and Malicet, J.: Absorption Spectra Measurements for the Ozone Molecule in the 350-830 nm Region, J. Atmos. Chem., 30, 291299, doi:10.1023/a:1006036924364, 1998.

Brohede, S., McLinden, C. A., Berthet, G., Haley, C. S., Murtagh, D., and Sioris, C. E.: A stratospheric $\mathrm{NO}_{2}$ climatology from Odin/OSIRIS limb-scatter measurements, Can. J. Phys., 85, 1253-1274, doi:10.1139/p07-141, 2007.

Brühl, C., Lelieveld, J., Höpfner, M., and Tost, H.: Stratospheric $\mathrm{SO}_{2}$ and sulphate aerosol, model simulations and satellite observations, Atmos. Chem. Phys. Discuss., 13, 11395-11425, doi:10.5194/acpd-13-11395-2013, 2013.

Bucholtz, A.: Rayleigh-scattering calculations for the terrestrial atmosphere, Appl. Opt., 34, 2765-2773, 1995.

Burrows, J. P., Richter, A., Dehn, A., Deters, B., Himmelmann, S., and Orphal, J.: Atmospheric remote-sensing reference data from GOME - 2. Temperature-dependent absorption cross-sections of O-3 in the 231-794 nm range, J. Quant. Spectr. Rad. Trans., 61, 509-517, doi:10.1016/s0022-4073(98)00037-5, 1999.

Cao, N., Fukuchi, T., Fujii, T., Collins, R. L., Li, S., Wang, Z., and Chen, Z.: Error analysis for $\mathrm{NO}_{2}$ DIAL measurement in the troposphere, Appl. Phys. B: Lasers and Optics, 82, 141-148, doi:10.1007/s00340-005-2050-8, 2006.

Chehade, W., Gorshelev, V., Serdyuchenko, A., Burrows, J. P., and Weber, M.: Revised temperature-dependent ozone absorption cross-section spectra (Bogumil et al.) measured with the SCIAMACHY satellite spectrometer, Atmos. Meas. Tech., 6, 30553065, doi:10.5194/amt-6-3055-2013, 2013.

Daumont, D., Brion, J., Charbonnier, J., and Malicet, J.: Ozone UV Spectroscopy I: Absorption Cross-Sections at Room Temperature, J. Atmos Chem., 15, 145-155, doi:10.1007/bf00053756, 1992.

Donovan, D. P., Whiteway, J. A., and Carswell, A. I.: Correction for nonlinear photon-counting effects in lidar systems, Appl. Opt., 32, 6742-6753, 1993.

Eberhard, W. L.: Correct equations and common approximations for calculating Rayleigh scatter in pure gases and mixtures and evaluation of differences, Appl. Opt., 49, 1116-1130, 2010.

Eisele, H. and Trickl, T.: Improvements of the aerosol algorithm in ozone lidar data processing by use of evolutionary strategies, Appl. Opt., 44, 2638-2651, 2005.

Fally, S., Vandaele, A. C., Carleer, M., Hermans, C., Jenouvrier, A., Merienne, M. F., Coquart, B., and Colin, R.: Fourier transform spectroscopy of the O-2 Herzberg bands. III. Absorption cross-sections of the collision-induced bands and of the Herzberg continuum, J. Mol. Spectrosc., 204, 10-20, doi:10.1006/jmsp.2000.8204, 2000.

Finger, F. G., Gelman, M. E., Wild, J. D., Chanin, M. L., Hauchecorne, A., and Miller, A. J.: Evaluation of NMC upperstratospheric temperature analyses using rocketsonde and lidar data, Bull. Amer. Meteorol. Soc., 74, 789-799, 1993

Garcia, R. R., Marsh, D. R., Kinnison, D. E., Boville, B. A., and Sassi, F.: Simulation of secular trends in the middle atmosphere, 1950-2003, J. Geophys. Res.-Atmos., 112, D09301, doi:10.1029/2006jd007485, 2007.

Godin, S.: Étude expérimentale par télédétection laser et modélisation de la distribution verticale d'ozone dans la haute stratosphère, $\mathrm{PhD}$ thesis (in French), Université Pierre et Marie Curie, Paris, 231 pp., 1987.

Godin, S., Carswell, A. I., Donovan, D. P., Claude, H., Steinbrecht, W., McDermid, I. S., McGee, T. J., Gross, M. R., Nakane, H., Swart, D. P. J., Bergwerff, H. B., Uchino, O., von der Gathen, P., and Neuber, R.: Ozone Differential Absorption Lidar Algorithm Intercomparison, Appl. Opt., 38, 6225-6236, 1999.

Godin-Beekmann, S. and Nair, P. J.: Sensitivity of stratospheric ozone lidar measurements to a change in ozone absorption cross-sections, J. Quant. Spectr. Rad. Trans., 113, 1317-1321, doi:10.1016/j.jqsrt.2012.03.002, 2012.

Godin-Beekmann, S., Porteneuve, J., and Garnier, A.: Systematic DIAL lidar monitoring of the stratospheric ozone vertical distribution at Observatoire de Haute-Provence (43.92 degrees N, 5.71 degrees E), J. Environ. Monit., 5, 57-67, doi:10.1039/b205880d, 2003.

Gorshelev, V., Serdyuchenko, A., Weber, M., Chehade, W., and Burrows, J. P.: High spectral resolution ozone absorption crosssections - Part 1: Measurements, data analysis and comparison with previous measurements around 293 K, Atmos. Meas. Tech., 7, 609-624, doi:10.5194/amt-7-609-2014, 2014.

He, H., Loughner, C. P., Stehr, J. W., Arkinson, H. L., Brent, L. C., Follette-Cook, M. B., Tzortziou, M. A., Pickering, K. E., Thompson, A. M., Martins, D. K., Diskin, G. S., Anderson, B. E., Crawford, J. H., Weinheimer, A. J., Lee, P., Hains, J. C., and Dickerson, R. R.: An elevated reservoir of air pollutants over the Mid-Atlantic States during the 2011 DISCOVER-AQ campaign: 
Airborne measurements and numerical simulations, Atmos. Env., 85, 18-30, doi:10.1016/j.atmosenv.2013.11.039, 2014.

Hinkley, E. D.: Laser monitoring of the atmosphere, Topics in applied physics, 14, Springer-Verlag, New York, 380 pp., 1976.

Höpfner, M., Glatthor, N., Grabowski, U., Kellmann, S., Kiefer, M., Linden, A., Orphal, J., Stiller, G., von Clarmann, T., Funke, B., and Boone, C. D.: Sulfur dioxide $\left(\mathrm{SO}_{2}\right)$ as observed by MIPAS/Envisat: temporal development and spatial distribution at $15-45 \mathrm{~km}$ altitude, Atmos. Chem. Phys., 13, 10405-10423, doi:10.5194/acp-13-10405-2013, 2013.

Hurst, D. F., Hall, E. G., Jordan, A. F., Miloshevich, L. M., Whiteman, D. N., Leblanc, T., Walsh, D., Vömel, H., and Oltmans, S. J.: Comparisons of temperature, pressure and humidity measurements by balloon-borne radiosondes and frost point hygrometers during MOHAVE-2009, Atmos. Meas. Tech., 4, 2777-2793, doi:10.5194/amt-4-2777-2011, 2011.

JCGM: International vocabulary of basic and general terms in metrology (VIM), Tech. Rep. JCGM 200:2008, International Bureau of Weights and Measures (BIPM), 2008a.

JCGM: Evaluation of measurement data - Guide to the expression of uncertainty in measurement (GUM), Tech. Rep. JCGM 100: 2008, International Bureau of Weights and Measures (BIPM), 2008 b.

JCGM: Evaluation of measurement data - An introduction to the "Guide to the expression of uncertainty in measurement" and related documents, Tech. Rep. JCGM 104: 2009, International Bureau of Weights and Measures (BIPM), 2009.

JCGM: International Vocabulary of Metrology - Basic and General Concepts and Associated Terms (VIM3), Tech. Rep. JCGM 200: 2012, International Bureau of Weights and Measures (BIPM), 2012.

Jenouvrier, A., Merienne, M. F., Coquart, B., Carleer, M., Fally, S., Vandaele, A. C., Hermans, C., and Colin, R.: Fourier transform spectroscopy of the O-2 Herzberg bands - I. Rotational analysis, J. Mol. Spectrosc., 198, 136-162, doi:10.1006/jmsp.1999.7950, 1999.

Leblanc, T., Sica R., van Gijsel, A., Godin-Beekmann, S., Haefele, A., Trickl, T., Payen, G., and Liberti, G.: Standardized definition and reporting of vertical resolution and uncertainty in the NDACC lidar ozone and temperature algorithms, ISSI Team on NDACC Lidar Algorithms Report, available for download at: http://www.issibern.ch/teams/ndacc/ISSI_Team_Report.htm, 2016a.

Leblanc, T., Sica, R. J., van Gijsel, J. A. E., Godin-Beekman, S., Haefele, A., Trickl, T., Payen, G., and Gabarrot, F.: Proposed standardized definitions for vertical resolution and uncertainty in the NDACC lidar ozone and temperature algorithms Part 1: Vertical resolution, Atmos. Meas. Tech., 9, 4029-4049, doi:10.5194/amt-9-4029-2016, 2016b.

Leblanc, T., Sica, R. J., van Gijsel, J. A. E., Haefele, A., Payen, G., and Liberti, G.: Proposed standardized definitions for vertical resolution and uncertainty in the NDACC lidar ozone and temperature algorithms - Part 3: Temperature uncertainty budget, Atmos. Meas. Tech., 9, 4079-4101, doi:10.5194/amt-9-40792016, 2016c.

Malicet, J., Daumont, D., Charbonnier, J., Parisse, C., Chakir, A., and Brion, J.: Ozone uv spectroscopy. 2. Absorption crosssections and temperature-dependence, J. Atmos. Chem., 21, 263-273, doi:10.1007/bf00696758, 1995.
McDermid, I. S., Godin, S. M., and Lindqvist, L. O.: Ground-based laser dial system for long-term measurements of stratospheric ozone, Appl. Opt., 29, 3603-3612, 1990.

McDermid, I. S., Beyerle, G., Haner, D. A., and Leblanc, T.: Redesign and improved performance of the tropospheric ozone lidar at the Jet Propulsion Laboratory Table Mountain Facility, Appl. Opt., 41, 7550-7555, 2002.

McGee, T. J., Gross, M., Ferrare, R., Heaps, W., and Singh, U.: Raman dial measurements of stratospheric ozone in the presence of volcanic aerosols, Geophys. Res. Lett., 20, 955-958, doi:10.1029/93g100751, 1993.

McGee, T. J., Whiteman, D., Ferrare, R., Butler, J. J., and Burris, J. F.: STROZ LITE - STRatospheric OZone Lidar Trailer Experiment, Opt. Engin., 30, 31-39, 1991.

McLinden, C. A., Fioletov, V., Boersma, K. F., Kharol, S. K., Krotkov, N., Lamsal, L., Makar, P. A., Martin, R. V., Veefkind, J. P., and Yang, K.: Improved satellite retrievals of $\mathrm{NO}_{2}$ and $\mathrm{SO}_{2}$ over the Canadian oil sands and comparisons with surface measurements, Atmos. Chem. Phys., 14, 3637-3656, doi:10.5194/acp-14-3637-2014, 2014.

Measures, R. M.: Laser remote sensing: fundamentals and applications, Wiley, 510 pp., 1984.

Mégie, G., Allain, J. Y., Chanin, M. L., and Blamont, J. E.: Vertical Profile of Stratospheric Ozone by Lidar Sounding from Ground, Nature, 270, 32-9-331, 1977.

Mégie, G. and Menzies, R. T.: Complementarity of UV and IR differential absorption lidar for global measurements of atmospheric species, Appl. Opt., 19, 1173-1183, 1980.

Merienne, M. F., Jenouvrier, A., Coquart, B., Carleer, M., Fally, S., Colin, R., Vandaele, A. C., and Hermans, C.: Improved data set for the Herzberg band systems of ${ }^{16} \mathrm{O}_{2}$, J. Mol. Spectrosc., 207, 120-120, doi:10.1006/jmsp.2001.8314, 2001.

Mohr, P. J., Taylor, B. N., and Newell, D. B.: CODATA recommended values of the fundamental physical constants: 2006, Rev. Mod. Phys., 80, 633-730, doi:10.1103/RevModPhys.80.633, 2008.

Müller, J. W.: Dead-time problems, Nucl. Instr. and Meth., 112, 4757, doi:10.1016/0029-554X(73)90773-8, 1973.

Papayannis, A., Ancellet, G., Pelon, J., and Mégie, G.: Multiwavelength lidar for ozone measurements in the troposphere and the lower stratosphere, Appl. Opt., 29, 467-476, 1990.

Pelon, J., and Mégie, G.: Ozone monitoring in the troposphere and lower stratosphere - evaluation and operation of a ground-based lidar station, J. Geophys. Res., 87, 4947-4955, doi:10.1029/JC087iC07p04947, 1982.

Press, W. H.; Flannery, B. P., Teukolsky, S. A., and Vetterling W. T.: Numerical Recipes: The Art of Scientific Computing (1st ed.), New York, Cambridge University Press, 818 pp., ISBN-13: 9780-521-88068-8, 1986.

Serdyuchenko, A., Gorshelev, V., Weber, M., Chehade, W., and Burrows, J. P.: High spectral resolution ozone absorption crosssections - Part 2: Temperature dependence, Atmos. Meas. Tech., 7, 625-636, doi:10.5194/amt-7-625-2014, 2014.

Strutt, J. W. (Lord Rayleigh): XXXIV. On the transmission of light through an atmosphere containing small particles in suspension, and on the origin of the blue of the sky, Philos. Mag., 47, 375384, doi:10.1080/14786449908621276, 1899. 
Uchino, O. and Tabata, I.: Mobile lidar for simultaneous measurements of ozone, aerosols, and temperature in the stratosphere, Appl. Opt., 30, 2005-2012, 1991.

Völger, P., Bösenberg, J., and Schult, I.: Scattering Properties of Selected Model Aerosols Calculated at UV-Wavelengths: Implications for DIAL Measurements of Tropospheric Ozone, Beitr. Phys. Atmosph. 69, 177-187, 1996.
Weitkamp, C.: Lidar: Range-Resolved Optical Remote Sensing of the Atmosphere, Springer Series in Optical Sciences, 102, Springer, New York, 460 pp., 2005. 